HID 48 (2021)

\title{
RESES, PASTOS Y TRIBUTOS EN LA BANDA MORISCA. LAS CIFRAS DEL PADRÓN DE LAS YERBAS DE MORÓN DE LA FRONTERA $(1532)^{1}$.
}

\author{
ABOUT CATTLE, GRASSES AND TRIBUTES IN THE BANDA \\ MORISCA. THE FIGURES FROM THE CENSUS OF THE GRASSES OF \\ MORON DE LA FRONTERA (1532)
}

\author{
José María Martín HuMANES \\ Universidad de Sevilla \\ jmmartinhumanes@us.es ORCID: https://orcid.org/0000-0002-9698-8636
}

RESUMEN: La presente contribución analiza el conjunto de datos ofrecidos por el padrón de las yerbas de Morón de la Frontera (1532), cuya edición vio la luz en esta misma revista en 2017 bajo el título "Ganadería y fiscalidad en la Banda Morisca: los primeros condes de Ureña y el padrón de las yerbas de Morón de la Frontera (1532)" (2017, n. 44). Fruto de los avances de esta investigación, este artículo estudia y edita también la conocida capitulación de la yerba, ordenanza que complementa a dicho padrón ganadero y que elaborada por los concejos de Morón de la Frontera, Arahal y la Casa de Osuna, venía a regular el aprovechamiento de los baldíos señoriales y su disfrute por los vecinos de ambas localidades.

PALABRAS ClAVE: Banda Morisca; ganadería; fiscalidad señorial; condes de Ureña; Morón de la Frontera; Arahal; padrón de las yerbas; capitulación de las yerbas; Juan Téllez Girón, II conde de Ureña.

ABSTRACT: This paper analyses the data provided by the padrón de las yerbas of Morón de la Frontera (1532), published in this journal in 2017 under the title "Ganadería y fiscalidad en la Banda Morisca: los primeros condes de Ureña y el padrón de las yerbas de Morón de la Frontera (1532)” (2017, no. 44). As a result

Recibido: 11-7-2020; Aceptado: 27-10-2020; Versión definitiva: 8-11-2020

1. Este trabajo se inserta dentro de las líneas de publicación del grupo de investigación HUM214 El reino de Sevilla en la Baja Edad Media, dirigido por la doctora Isabel Montes Romero-Camacho y financiado por la Consejería de Innovación, Ciencia y Empresa de la Junta de Andalucía.

Abreviaturas utilizadas: AHN $=$ Archivo Histórico Nacional; AMMF $=$ Archivo Municipal de Morón de la Frontera; ARCHGR = Archivo de la Real Chancillería de Granada; ANM = Archivo de Protocolos Notariales de Morón de la Frontera; cg = cabezas de ganado; ug = unidades ganaderas.

Copyright: (C) Editorial Universidad de Sevilla. Este es un artículo de acceso abierto distribuido bajo los términos de la licencia de uso y distribución Creative Commons Reconocimiento-NoComercialSinObraDerivada 4.0 (CC BY-NC-ND 4.0) 
of this research, this article also studies and publishes the capitulación de la yerba, an ordinance that complements the census of livestock and was prepared by the councils of Morón de la Frontera, Arahal and the House of Osuna, to regulate the use of the uncultivated lands and usage by the neighbors of both localities.

KEYWORDS: Banda Morisca; stockbreeding; Lordly taxation; The counts of Ureña; Morón de la Frontera; Arahal; Census of the grass; Capitulation of the grass; Juan Téllez Girón, II count of Ureña.

\section{INTRODUCCIÓN}

Desde época bajomedieval la ganadería fue la principal fuente de riqueza de las comarcas sevillanas limítrofes con el reino nazarí de Granada. En territorios fronterizos como la Banda Morisca su impronta quedó fuertemente marcada en su poblamiento, perviviendo hasta bien entrada la modernidad. De su relevancia en estos espacios rurales dan buena cuenta documentos como el que presentamos en 2017, un repartimiento ganadero elaborado para la villa de Morón de la Frontera en 1532 y que sus contemporáneos conocieron popularmente como el padrón de las yerbas ${ }^{2}$. Como ya se señaló, el instrumento buscaba determinar la contribución que cada vecino debía realizar a la renta anual impuesta por los condes de Ureña a los concejos de Morón de la Frontera y Arahal por razón del uso y disfrute de sus baldíos. Su edición supuso un aporte más a la escasa nómina de fuentes ganaderas existentes para el reino de Sevilla y la campiña hispalense, permitiéndonos acceder a valiosas informaciones socio-económicas sobre dicho mundo rural, sus particularidades comarcales y las problemáticas que afectaban a sus sectores productivos. Nuevos materiales, en definitiva, que refuerzan el debate y contribuyen al conocimiento de la sociedad rural andaluza ${ }^{3}$. Tras la presentación de la fuente en la primera entrega, en este artículo abordaré el análisis de sus cifras y editaré la capitulación de la yerba (1519), un documento recientemente localizado que complementa al propio padrón y donde se señalan las disposiciones que regulaban el aprovechamiento de las baldíos.

Así pues, a modo de sumario, éstas serán las cuestiones que trataremos a lo largo de las próximas páginas. En primer lugar, tomando como referencia los estudios publicados sobre el sector ganadero en el antiguo Reino de Sevilla, nos aproximaremos a la villa de Morón de la Frontera para conocer las cifras generales que definían por entonces a la cabaña moronense: el número de cabezas de ganado que la componían, la clasificación tipológica de las reses, su distribución en especies y

2. Martín Humanes, 2017.

3. Una aproximación a la cuestión ganadera bajomedieval y a la situación particular de la campiña sevillana en su tránsito a la modernidad en: Andreolli, 2001-2002; Argente Del Castillo Ocaña, 1991, Borrero Fernández, 2012; Cabrera Muñoz, 2002; Carmona Ruiz, María Antonia, 1996, 1997a, 1997b, 2000a, 2000b; Clemente Ramos, 2001; Devís Márquez, 1997, García Fernández, 2005; González Jiménez, 1987, 1996; González Jiménez, García Fernández (eds.), 1992, Martín Gutiérrez, 2015; Martín Humanes, 2015, Monsalvo Antón, 2010; Villalonga Serrano, 2007; Clemente Ramos, 2013, 2014a, 2014 b. 
cómo éstas se proyectaban fiscalmente a la hora de su cuantificación y registro en el padrón. A continuación, me centraré en la distribución de la propiedad ganadera local, deteniéndome en el papel que jugaban este tipo de activos en el conjunto de los patrimonios de los vecinos de Morón de la Frontera y muy especialmente en los de los plutócratas locales, apuntando su papel en sus estrategias de dominación, reproducción y ascenso social. Acto seguido, ya en tercer lugar, he tratado específicamente la cuestión de la capitulación de la yerba, señalando todos los detalles que rodearon tanto a la negociación de Morón de Frontera y Arahal con Juan Téllez Girón, como el texto que nació de aquel acuerdo, analizando cada una de sus cláusulas y sus implicaciones para los vecinos afectados. Por último, para cerrar la contribución, se incorpora un último epígrafe dedicado a exponer las conclusiones generales que se desprenden de ambas entregas, al que le sigue el repertorio bibliográfico y, a modo de anexo, la transcripción de la capitulación de las yerbas. Todo ello, apoyado e ilustrado por un amplio catálogo de gráficos e imágenes elaborados específicamente para la ocasión.

\section{LA CABAÑA MORONENSE: CABEZAS DE GANADO, ESPECIES, TRIBUTACIÓN Y RECAUDACIÓN}

Como ya se mencionó en la primera entrega, gracias al padrón de las yerbas sabemos que en Morón de la Frontera existían un total de 18.700 animales aproximadamente, predominando en número claramente el ganado menor. Concretamente, de ellos, casi 14.000 eran de especies menores mientras que 4.800 eran de especies mayores (74 \% / $26 \%$ ), cifras muy en la línea de lo expuesto por la profesora Carmona Ruíz para la tierra de Sevilla y en especial para la comarca de la campiña.

Aunque bastante representativas de la realidad ganadera local y similares a la tendencia comarcal, las cifras ofrecidas por el padrón moronense deben matizarse, pues no son absolutas. De acuerdo con lo dispuesto por capitulación de las yerbas en su capítulo primero, del registro total de animales quedaron fuera del cómputo del padrón especies por entonces muy populares como caballos, mulos y asnos, de ahí que esas cuantías resultaran siendo superiores a lo indicado por el instrumento $y$, por extensión, distinta también la proporción entre especies menores y mayores. Del mismo modo, conviene precisar que junto a los animales propiedad de los vecinos, en el canpo e término de Morón de la Frontera pastaron simultáneamente muchos más animales aparte de los computados y que éstos, por ser propiedad de foráneos sin vinculación alguna con la villa a efectos de vecindad, aquí, en este estudio, no aparecen reflejados a efectos tributarios ni cuantitativos. En efecto, en relación con la densidad ganadera que presentaba este territorio, solo contamos con algunas declaraciones de la época que ofrecen testimonio. Precisamente éstas, las reses foráneas, venían agravando los problemas de escasez de pasto sufridos por los locales y tras 1519, con el acuerdo alcanzado, serían las grandes perjudicadas quedando privadas de seguir trasladándose a esta localidad. 


\section{Distribución de la cabaña ganadera moronense (1532)}
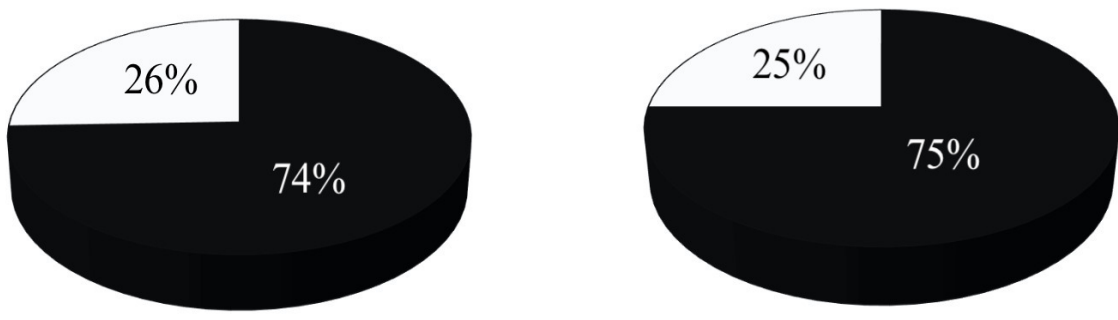

\section{Cabaña ganadera campiña sevillana (ppos. s. XVI)}

-Ganado menor $\square$ Ganado mayor

Gráfico 1. Distribución de la cabaña ganadera moronense (1532) vs cabaña ganadera de la campiña sevillana a ppos. de s. XVI. Datos expresados en cabezas de ganado ${ }^{4}$.

Como es bien sabido, la elevada concentración de animales y, particularmente, la abundancia de especies menores en la campiña respondía a las características ambientales y políticas que mostraba este territorio durante los últimos siglos y, más certeramente, a las consiguientes demandas que los mercados regionales establecían del mismo con relación a su potencial de producción cárnica, materias primas y derivados destinados al consumo humano. Esta circunstancia contrasta, por ejemplo, con el perfil que presentaban las poblaciones de la comarca del Aljarafe (situadas al oeste de la actual provincia de Sevilla), donde el reducido número animales se conjugaba con el predominio de especies mayores, fundamentalmente ganado boyal, pieza clave de las actividades agrícolas y eje de la economía regional.

Las especies menores en Morón de la Frontera se distribuían numéricamente de forma bastante equitativa, estando conformadas por 6.050 cabezas de ganado caprino (43\%), 4.265 cabezas de ganado lanar (31\%) y 3.607 cabezas de ganado porcino $(26 \%)$. Estos datos no coinciden plenamente con los observados para el resto de la campiña, donde la especie predominante fue el ganado lanar, seguido del porcino y el caprino. Dichas variantes se antojan lógicas y habituales en este tipo de análisis elaborados sobre amplias muestras y de numerosas poblaciones. No en vano, el que una determinada localidad mostrase mayor inclinación por una $u$ otra especie respondía a las necesidades que planteaba su propio vecindario -abastecimiento, comercio, etc.- y a las posibilidades ambientales que ofrecía su término ${ }^{5}$. En este sentido, la biodiversidad del alfoz moronense brindaba por

4. Los datos sobre la cabaña ganadera de la campiña sevillana, así como la mayoría de los aquí expuestos y tomados como referencia en nuestras comparativas, han sido obtenidos de los padrones bienes aportados por la profesora Carmona Ruíz en los anexos de su tesis doctoral. Vid. Carmona Ruiz, 1995.

5. Tómese en consideración que el alfoz histórico de Morón de la Frontera transitaba entre las comarcas de la campiña y la sierra sur sevillana, de perfiles ambientales muy distintos. Sobre este particular, vid. Morilla Cala, 1991, 1992, 1996. 


\section{Distribución por especies de la cabaña moronense. Año de 1532}

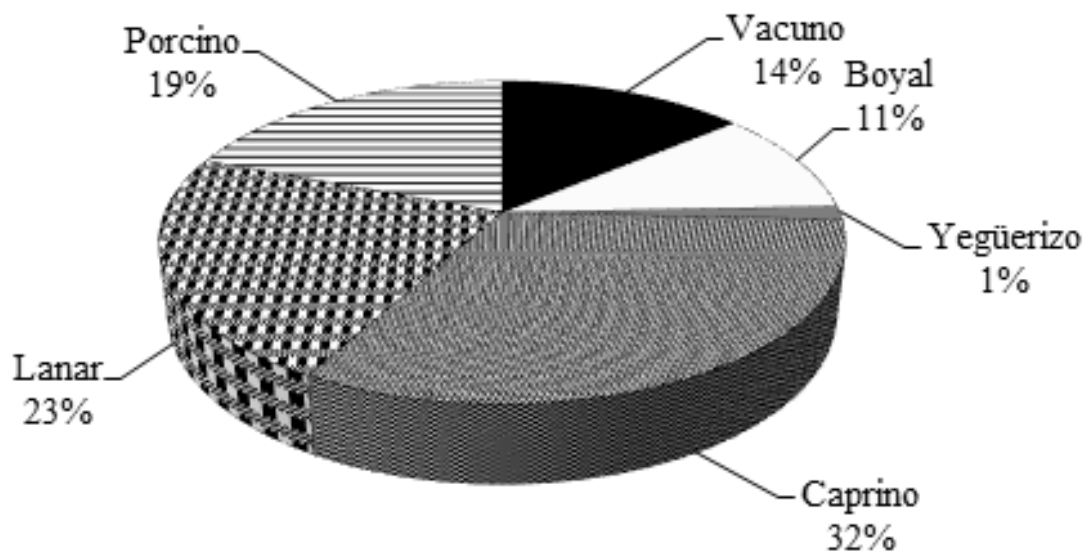

Gráfico 2. Distribución por especies de la cabaña moronense (1532). Datos expresados en cabezas de ganado.

entonces entornos muy propicios para cada una de estas especies menores. Para el ganado caprino, las escarpadas lomas serranas presentaban los pastos y el espacio suficiente para su crianza y reproducción; para el ovino, se disponía de los extensos campos de cereal de la campiña, que tras la siega de las mieses dejaban los rastrojos necesarios para su alimentación; y en lo que al ganado porcino respecta, las amplias zonas de encinares y alcornoques creaban el ecosistema perfecto para su pleno desarrollo.

A diferencia de las especies menores, las mayores sí mostraban cifras mucho más extremas en su composición. Ello se debe, en parte, a que en el repartimiento sólo tuvieron representación las subespecies bovinas y equinas -el ganado bravo no, por ejemplo-, y en el caso de los équidos sólo aparecían recogidas las yeguas y no así los caballos, privados de acceder a los pastos señoriales. Ello ha provocado que las cifras resultantes se muestren muy marcadas dentro ya de una tendencia de por sí clara, en la línea también de lo expuesto por Carmona Ruíz ${ }^{6}$. Teniendo en cuenta estas consideraciones, las especies mayores van a arrojar cifras de 4.566 cabezas de ganado bovino (el $95 \%$ de todo el ganado mayor) y de 247 cabezas de ganado équidas ( $5 \%$ ). De haber podido lograr una muestra completa, a buen seguro las cifras habrían de ser sensiblemente corregidas en varios de sus puntos, aunque siempre dentro de esta tendencia dominadora de las reses bovinas.

En el caso concreto de las especies mayores, el torrente de datos que aporta el repartimiento nos permite también profundizar en la proporción y porcentajes que muestran sus distintas subespecies. En el caso de los bovinos, por ejemplo, el

6. Carmona Ruíz, ob. cit., pág. 553. Gráfico no. 21. 
ganado vacuno sumaba 2.574 cabezas, lo que suponía un $56 \%$ del total, seguido muy de cerca por el ganado boyal, con 1.957 cabezas y un $43 \%$ del total. En el caso de los équidos, como se mencionó anteriormente, sólo se registran las yeguas -y solo las dedicadas a la trilla-, lo que se traduce en que el yegüerizo represente el $100 \%$ del mismo, algo improbable fuera del propio padrón si tenemos en cuenta que esta comarca, junto con el Aljarafe, fue la que acogió mayor número de ganado caballar ${ }^{7}$.

Por tanto, en lo que a porcentajes del número total de animales se refiere, se concluye que la cabaña moronense registrada en el padrón estaba compuesta en un $32 \%$ por ganado caprino, en un $23 \%$ por ganado lanar, un $19 \%$ de ganado porcino, un $14 \%$ de ganado vacuno, $11 \%$ de ganado boyal y $1 \%$ de ganado yegüerizo.

En el epígrafe $\mathrm{n}^{\circ} 2$ del anterior artículo ya ofrecí algunos apuntes sobre el régimen de tributación que aplicaron los concejos de Morón de la Frontera y Arahal entre sus vecinos para pagar la renta de la yerba ${ }^{8}$. No obstante, queda por reseñar lo tributado por los moronenses, lo que pechaba cada animal de acuerdo con su especie y el aporte general que cada una de las especies realizaron a la cuantía final recaudada.

Antes de entrar en materia es preciso recordar que sobre la muestra empleada solo disponemos de datos para Morón de la Frontera y no para Arahal (aldea jurisdiccionalmente sometida a la villa matriz), de la cual no se han conservado ninguno de estos instrumentos, y que en el caso de Morón de la Frontera solo se ha conservado el padrón para un año, el de 1532.

Asimismo, para sufragar los 50.000 maravedís correspondientes a la renta de la yerba del año de 1532, el Concejo de Morón de la Frontera debió abonar un total de 20.240 maravedís procedentes del pecho de 5.060 unidades ganaderas (en adelante ug.), mientras que el Concejo de Arahal tuvo que hacer lo propio aportando 31.684 maravedís procedentes del pecho de $7.921 \mathrm{ug}$., quedando un remanente, tal y como señala la fuente, de myle e noveçientos e treinta e quatro maravedís para las cosas de ambos conçejos. Debe señalarse también que el número de unidades ganaderas computadas para Morón de la Frontera contrasta con las 5.303,5 ug. que arroja por la consulta directa del padrón, la cual he empleado como referencia en mis estimaciones. La distorsión entre las cifras computadas y las que se menciona en la parte final del documento (243 ug) puede responder al tratamiento contable recogido en el noveno artículo de la capitulación y que fijaba la tributación anual de reses a renta o vendidas por sus dueños antes de cumplido el año.

Para conocer la naturaleza fiscal y contable que aplicó a cada uno de los animales es preciso realizar la conversión de las cabezas de ganado a unidades ganaderas, la unidad fiscal de referencia en esta ocasión. El procedimiento en cuestión era utilizado por los contemporáneos con la finalidad de saber la cuantía total que debía pechar en dineros el propietario de una cabaña compuesta por animales

7. En relación con la variedad caballar, de la que no tenemos datos en esta muestra, deben tomarse en cuenta las obligaciones que conllevaba la dignidad de la caballería de cuantía, con gran presencia en Morón de la Frontera, y su requisito expreso de mantenimiento de caballo y armas.

8. Martín Humanes, 2017, pág. 216 y ss. 


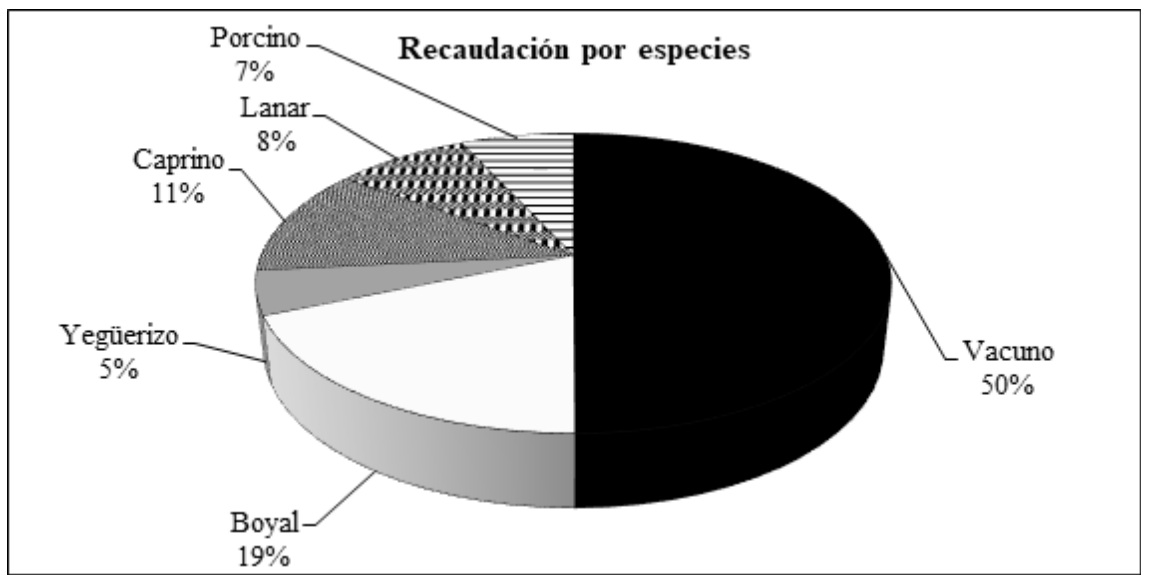

Gráfico 3. Recaudación por especies (1532).

de muy distintas especies. Además de los testimonios ya ofrecidos por el propio Alonso Guisado, escribano del Arahal ${ }^{9}$, también las autoridades de los concejos de Morón de la Frontera y Arahal ofrecen una clara descripción de este procedimiento en la capitulación de 1519, indicando:

Et en el otavo capitulo dezís que la orden que days los ofiçiales de anbas villas quel repartimyento $/{ }_{4 r}$ de los dichos çinquenta myle maravedis que me aveys de dar e pagar la dicha yerva es que todo el ganado se faga vacas, de tal manera que dos bueyes paguen por vna vaca, porque andan en dehesas, e diez ovejas, e diez cabras, o diez carneros, o diez puercos o puercas, o diez cochinos por vna vaca, e desta manera se repartan por cantidad lo que cada vno toviere, e que cada vna yegua por vna vaca, e que los cochynos e corderos se an de contar diez por vna vaca, e que an de ser todos los que estuvieren naçidos por San Juan de junyo de cada año ${ }^{10}$.

De tal modo, tal y como indica el propio padrón, cada unidad ganadera computada tributó a 4 maravedís (1 vaca, 1 yegua, 2 bueyes, 10 cabras, 10 ovejas y 10 cochinos). En base a este testimonio, los casi 18.700 animales con que contaba Morón de la Frontera se van a transformar en 5.303,5 ug., de las cuales 3.835 sería fruto de la conversión del ganado mayor (72 \%) y 1.392,5 del ganado menor $(28 \%)$. Ello muestra que la tributación realizada por especies mayores y menores fue muy desigual, y que los dueños de las primeras fueron con diferencia los que soportaron la práctica totalidad del peso del pago anual de la renta de la yerba (la proporción entre las especies bovinas y equinas fue de $93 \%$ a $7 \%$. Tal contraste no se observa en el caso del ganado menor, pues las especies, al tener un coeficiente fiscal bajo y muy similar en todos los casos, vuelven a mostrar un aporte muy

9. Martín Humanes, 2017, pág. 220, Cit. n. 14.

10. AHN, Osuna, C. 3434 , D. 24 , fol. $3 \mathrm{v}-4$ r. Vid. et. ARCHG, caja 1377 , pieza 6 , fol. $13 \mathrm{v}$. 
parejo, aportando el ganado caprino el $43 \%$ de todo lo tributado por los menores, el $31 \%$ el lanar y el $26 \%$ el porcino).

En cifras totales y por especies, encontramos que ahora es el ganado vacuno el que va a aportar el $50 \%$ del total de lo recaudado, el ganado boyal el $19 \%$, el ganado caprino el $11 \%$, el ganado lanar el $8 \%$, el porcino el $7 \%$ y el yegüerizo el $5 \%$.

\section{CABAÑAS Y PROPIETARIOS}

Con objeto de centrar la cuestión sobre la distribución de la propiedad ganadera, conviene arrancar este epígrafe indicando que los veinte mayores propietarios de Morón de la Frontera (5 \% del vecindario aprox.), concentraban en sus manos casi el $50 \%$ de todos los animales. Concretamente, declaran ser poseedores de 8.699 reses, el $46 \%$ de las 18.737 contabilizadas. Esta circunstancia, por todos los lugareños consabida, transcendía el plano fiscal y económico e impregnaba los usos populares y hasta la jerga cotidiana de sus gentes. Así, cuando en los ordenamientos municipales se alude explícitamente a los señores del ganado, los capitulares no empleaban un apelativo gratuito. Con esta voz ruda pero expresiva se referían a este reducido grupo de propietarios cuyo papel en la economía y en la comunidad era tan relevante que el concejo los llamaba a capítulo si tocaba regular aspectos tocantes al sector, para que asesoraran e intervinieran en las deliberaciones - eso, si no formaban parte ya de la propia corporación, bien de manera directa o a través de personas interpuestas-.

Estos datos iniciales muestran con claridad que la riqueza ganadera estuvo concentrada en pocas manos y que por tanto su reparto fue desigual y poco equitativo entre su vecindario. Estas mismas conclusiones generales han sido expuestas anteriormente por diversos investigadores que se han acercado a esta comarca sevillana mediante el estudio de padrones de bienes de localidades próximas ${ }^{11}$. Las diferencias entre propietarios se van revelando conforme se avanza en la lectura de este instrumento. Observándolas desde la perspectiva fiscal que marca el padrón y el coeficiente establecido, la muestra resultante dibuja una estructura piramidal de extrema configuración en donde existió un $10 \%$ de vecinos que por sus exiguas posesiones siquiera se vio obligado a tributar por ellas. Llama poderosamente la atención un porcentaje tan elevado en una región donde el ganado no sólo constituía la principal fuente de riqueza de sus habitantes, sino también la primera vía de cara al sostenimiento económico de muchas familias de bajos recursos.

Tras este primer grupo, en sentido ascendente les seguía el $66 \%$ del vecindario. Éste apenas si poseyó entre 1 y 10 unidades ganaderas, lo que en la práctica se traducía en una pequeña cabaña dedicaba al autoabastecimiento y a sus labores cotidianas en el minifundio. Ya en cotas más elevadas figuraba el $18 \%$ restante de la población, que presentaba una disposición claramente jerarquizada y con sensibles diferencias internas en cuanto al montante de su cabaña (entre las 11 y

11. Vid. Carmona Ruiz, 1995, 2001, 2011, 2014. Borrero Fernández, 2012. 


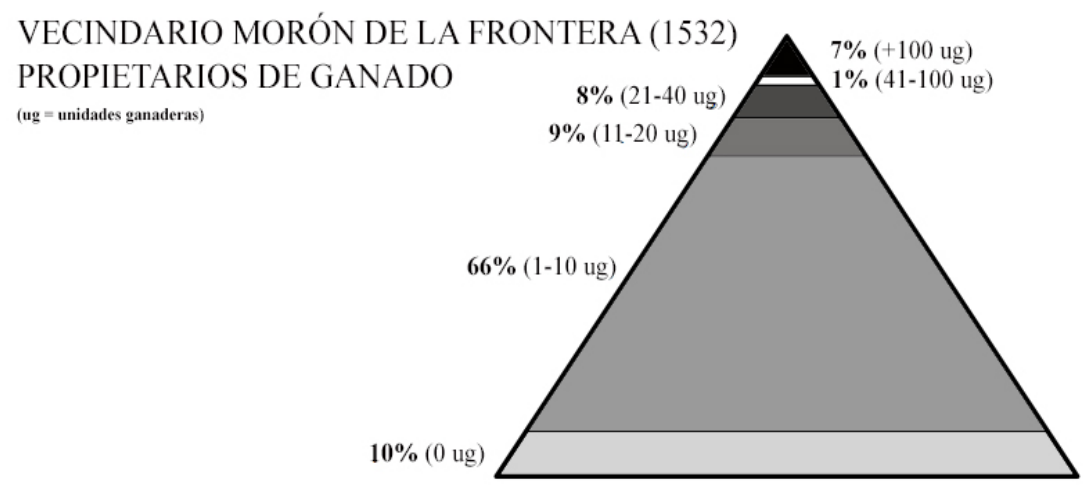

Gráfico 4. Vecindario Morón de la Frontera (1532). Propietarios de ganado. Datos expresados en unidades ganaderas.

las $100 \mathrm{ug}$ ). Tras estos escalafones, en la cúspide de este segmento encontramos a los principales de la localidad, una suerte de potentados locales que dispusieron de más de 100 unidades ganaderas que dedicarían a la labranza de sus tierras y a su comercialización.

La distribución de la propiedad y las diferencias por especies fueron factores que influyeron de manera directa en las distintas formas de explotación ganadera. En efecto, pese a que Morón de la Frontera y el conjunto de la campiña sevillana eran tierras dominadas por el ganado menor y la especie vacuna, la progresiva puesta en explotación de una parte importante de este territorio provocaría que los bueyes alcanzaran también un evidente protagonismo. De hecho, el buey de arada, por su versatilidad en el campo y por las distintas posibilidades que ofrecía a la hora de explotarlo, fue la especie más extendida y que mayor predicamento logró entre el conjunto del vecindario moronense. Tanto, que el $80 \%$ de los vecinos de Morón de la Frontera disponían de este animal en posesión y quizás también en propiedad (ocho de cada diez hogares, el animal con mayor presencia en los hogares locales), un detalle muy interesante que me ha permitido distinguir tres tipos de ganaderos en función del volumen de su boyada y del sistema de explotación adoptado $^{12}$

Por un lado, se observa un primer grupo de propietarios muy numeroso, mayoritario (64\%), que dispuso entre 1 y 5 bueyes que empleaban para labrar sus pequeñas fincas. Este perfil de propietarios fue el más extendido en la localidad y también en toda la comarca de la campiña en consonancia con la extensión del minifundio ${ }^{13}$. De hecho, para las localidades vecinas este mismo porcentaje asciende

12. Y ello, pese a su precio de mercado por entonces en Morón de la Frontera, $4.500 \mathrm{mrs} / \mathrm{unidad}$, una cantidad elevada y superior incluso al precio del ganado vacuno.

13. Durante las primeras décadas del s. XVI fueron muy numerosas las licencias concedidas por el concejo de Morón para la apertura de roças en espacios todavía incultos. Una medida que, por otra parte, contó con la aprobación del poder señorial. AMMF, Gobierno, leg. 2, fol. 162v. 


\section{Propietarios de ganado boyal (en cabezas de ganado)}

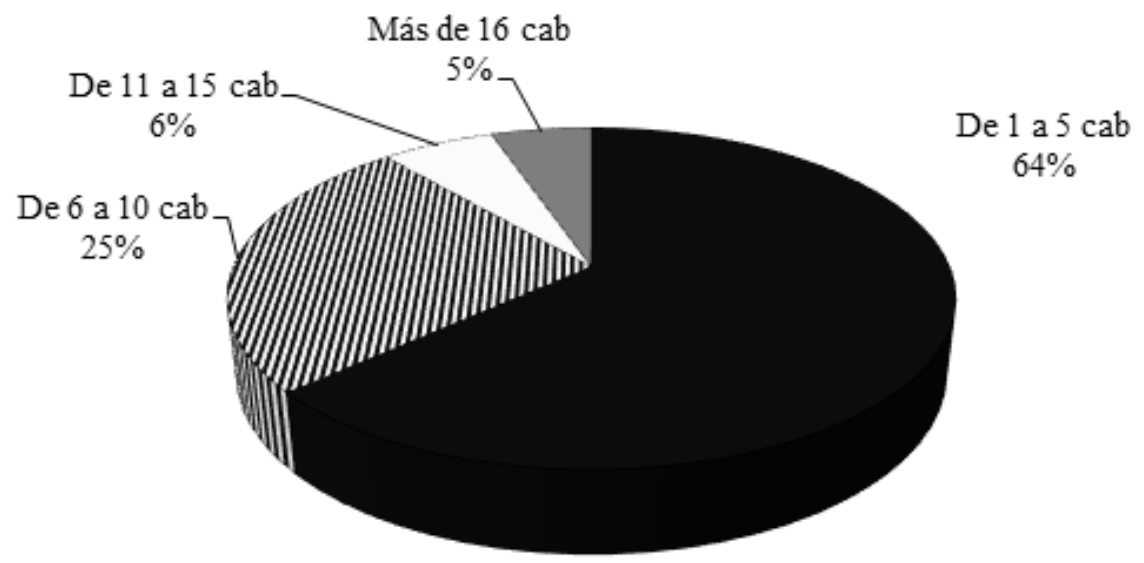

Gráfico 5. Propietarios de ganado bovino. Datos expresados en cabezas de ganado.

hasta el $75 \%$. A continuación le seguía un grupo de propietarios que poseían entre 6 y 10 bueyes, sensiblemente menor que el primero (25\%), y un tercer grupo intermedio, ya muy reducido (6\%), de los que tenían entre 11 y 15 ejemplares. Pese a ser propietarios acomodados y de cierto caudal, igualmente empleaban las reses para las tareas cotidianas en sus tierras, éstas de pequeña y mediana extensión, y que en algunos casos, muy pocos, pudieron llegar a ser comercializadas a renta como fuerza de trabajo. Por último, encontramos un último grupo, tan escaso como el anterior, (5\%) que gracias a la cría y reproducción intensiva dispusieron de una cabaña de bueyes muy numerosa, de más de 16 reses, que dedicaban a trabajar sus tierras y comercializar con ellas en régimen de alquiler, como fuerza de trabajo. Los primeros volúmenes del archivo de notarías de Morón de la Frontera ofrecen numerosos contratos de este tipo ${ }^{14}$.

Como puede apreciarse en el gráfico $\mathrm{n}^{\circ} 5$, la tenencia del ganado boyal se concentraría en muchas manos, al contrario de lo que sucedería con las vacas. El ganado vacuno, también por sus propias características, presentaba una distribución muy diferente. De entrada, fue una de las especies más numerosa y la primera de cuantas conformaba el ganador mayor, sin embargo sus niveles de concentración fueron muy elevados, pues pese a su precio apenas el $38 \%$ de los vecinos dispuso de este animal entre sus posesiones (en otras palabras, solo en cuatro hogares de cada diez) ${ }^{15}$. Las vacas formaban parte de los activos fijos y más seguros de los ganaderos locales, su principal fuente de riqueza, y a diferencia del buey sus dueños se dedicaban a su crianza y reproducción para la obtención de materias

14. ANMF, leg. 305. Escribanía de Juan de Palma (1532-1534).

15. Apreciadas en $3.000 \mathrm{mrs} / \mathrm{u}$ las vacas paridas, $2.000 \mathrm{mrs} / \mathrm{u}$ las vacas vacías (valores obtenidos de los inventarios de bienes manejados en la elaboración del estudio). 


\section{Propietarios de ganado vacuno (en cabezas de ganado)}

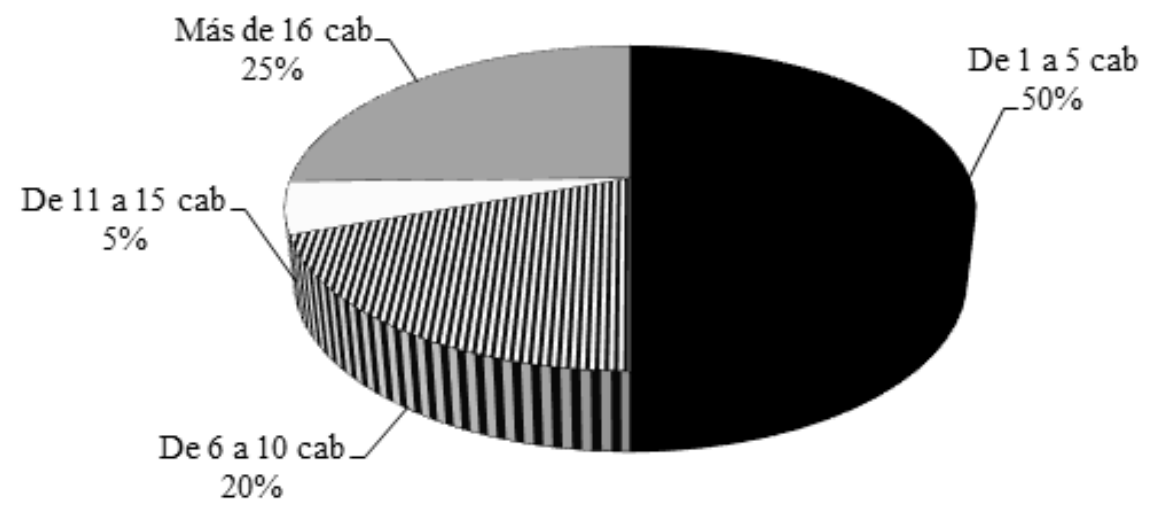

Gráfico 6. Propietarios de ganado vacuno. Datos expresados en cabezas de ganado.

primas - carne, cuero, leche, cebo, etc.-y productos secundarios -quesos, jabones, vestimentas, etc.- que posteriormente comercializaban. En función del número de reses de la vaquería y del sistema de explotación adoptado se distinguen también varios tipos de vaqueros en Morón de la Frontera.

En primer lugar, existió un $50 \%$ de éstos que dispusieron de no más de 4-5 ejemplares, los cuales criaban y mantenían para la obtención de materias primas y productos secundarios destinados a consumo propio -en el resto de la campiña este porcentaje es algo menor-. Sin descartar del todo esta posibilidad, en muy pocos casos vamos a observarlas como animal de tiro y participando en las labores agrícolas como sucedía en el Aljarafe con las vacas de arada ${ }^{16}$. A éstos, les seguía un grupo intermedio, de en torno al $20 \%$ de los vaqueros, que disponían de entre 6-10 (19 \%) y 11-15 (5\%) cabezas de ganado. En su mayoría, estas pequeñas cabañas estaban orientadas al autoabastecimiento, si bien en un pequeño porcentaje pudieron participar en la comercialización de productos secundarios en el mercado local. Y finalmente, se observa un último bloque de propietarios que representa el $25 \%$ del total -justamente el mismo porcentaje que en el resto de las localidades de la campiña-, y que tendrían una cabaña muy numerosa, siempre por encima de las 16 cabezas de ganado. Esta clasificación genérica no debe impedirnos profundizar en este último segmento y comprobar que existieron casi una decena de ganaderos que acumularon más de 50, 100 y 150 reses, cantidades por sí mismas muy elevadas si tenemos en cuenta el monto total de la cabaña local. De estas reses, una mínima parte iría destinada a consumo propio y la amplia mayoría de ellas a producir de manera intensiva, para así posteriormente sacar al mercado local y comarcal cantidades importantes de materias primas y productos secundarios.

16. Borrero Fernández, 2012. 


\section{Propietarios de ganado yegüerizo (en cabezas de ganado)}

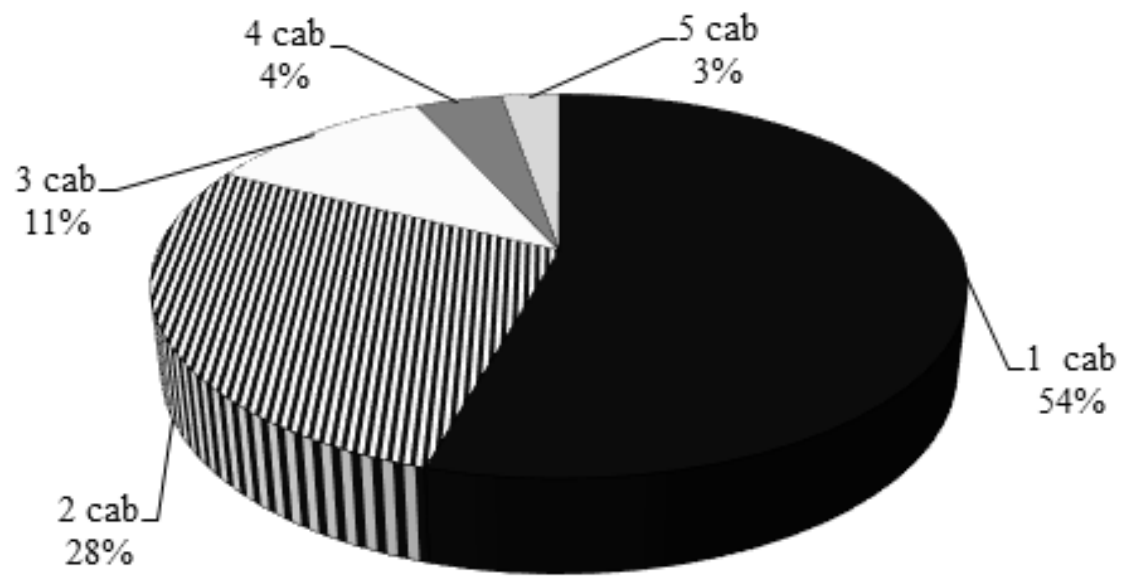

Gráfico 7. Propietarios de ganado yegüerizo. Datos expresados en cabezas de ganado.

Haciendo valer el volumen de su cabaña, estos grandes ganaderos debieron participar también en las ferias comarcales de compra/venta de ganado, donde alcanzaron gran demanda los ejemplares más jóvenes y las líneas más fértiles.

Pese a que el ganado yegüerizo fue el más escaso de cuantos aparecen recogidos en el padrón (247 ejemplares), curiosamente en lo que a la distribución de la propiedad se refiere presentaba cifras muy similares al vacuno, por entonces uno de los más extendidos entre los vecinos. En efecto, según las cifras resultantes de nuestro análisis, fue un animal bastante extendido y accesible. El $54 \%$ de los vecinos tenían en propiedad algún ejemplar (cinco de cada diez hogares), el cual era usado, fundamentalmente, para la crianza -función reproductora-, en las labores del campo - trilla y recogida de las mieses- y como medio de transporte de personas o carga de mercancías. Muy posiblemente, lo apreciados que estaban en el mercado ${ }^{17}$, el rol secundario adoptado en el campo y el importante número de caballos existentes -un factor también importante-, hicieron que el número de yeguas por propietario no fuera muy alto. Fueron mayoritarios quienes dispusieron de un sólo ejemplar, casi un $60 \%$ del total, mientras que el $40 \%$ restante se repartió entre quienes disfrutaban de 2 unidades (28\%), 3 (11\%), 4 (4\%) y 5 (3\%)-cifras nuevamente muy similares a las que presentan las poblaciones de la campiña-.

Aunque los caballos no aparezcan contabilizados en este repartimiento por no ser admitidos en los pagos señoriales, sabemos que tuvieron un enorme predicamento en la localidad tanto por el acento ganadero de la región como por la impronta militar de la plaza y las obligaciones que comportaba la caballería cuantía. En efecto, por mandato regio, los caballeros de cuantía moronenses, en

17. Apreciadas entre los 6.000 y los $10.000 \mathrm{mrs}$ (valores obtenidos de los inventarios de bienes manejados en la elaboración de este estudio). 


\section{Propietarios de ganado caprino (en cabezas de ganado)}

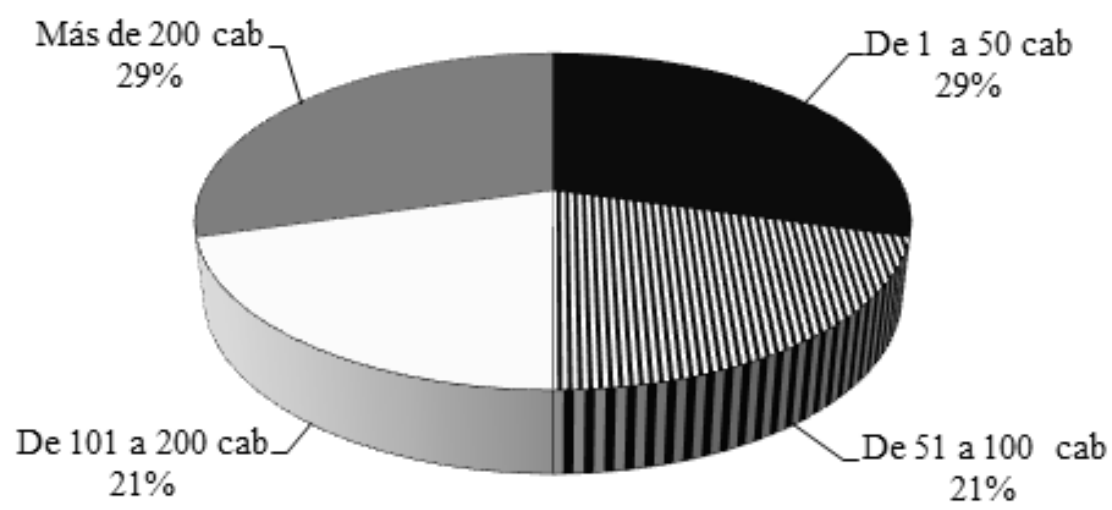

Gráfico 8. Propietarios de ganado caprino. Datos expresados en cabezas de ganado.

torno a un centenar de vecinos, debían tener y mantener en perfectas condiciones un caballo que les permitiera cumplir con cualquier servicio militar sobrevenido. Sólo tomando en cuenta este dato podemos advertir que los valores reales sobre la presencia del ganado caballar en Morón de la Frontera debieron ser más elevados que los finalmente resultantes de nuestro análisis -elaborados solo en base al yegüerizo- ${ }^{18}$.

Pese a su importancia en las tareas agrícolas y en las labores cotidianas, no disponemos de información sobre el ganado híbrido. Al no ser admitidos en los pagos señoriales ni mulos ni asnos, no aparecen cuantificados en el padrón. Tampoco las reses bravas, también con mucho predicamento en la región ${ }^{19}$.

A diferencia del ganado mayor, el ganado menor, por su propia naturaleza y proyección comercial, presentaba unos índices de concentración mucho más elevados. Solo entre el 5\%-10\% del vecindario declara la tenencia de estas especies (uno de cada diez hogares, en el mejor de los casos), lo que en última instancia se tradujo en rebaños muy numerosos en manos de pocos vecinos cuyas cabañas llegaban a representar, en ocasiones, más del $50 \%$ del total de las reses de dicha

18. Sobre las obligaciones que comportaba la cuantía a los caballeros de Morón, vid. AHN, Osuna, C.90, D. 1-11, doc. 11, fol. 9v. (1462, octubre, 2. Porcuna). Confirmación de privilegios a Morón de la Frontera y su aldea del Arahal realizada por Enrique de Figueredo, tutor y guardador de su señor, Alfonso Téllez Girón, I conde de Ureña. Vid. et. ARCHG, caja 2279, pieza 3, fol. 74v. (1538, $4,18)$ Relación de los caballeros de cuantía inserta en el pleito que el bachiller Alonso de Humanes libraba contra el Concejo de Morón de la Frontera en la Real Audiencia y Chancillería de Granada.

19. Sobre el predicamento de las reses bravas, vid. AHN, Sección Osuna, C.82, D.45-46, fol. 8v. (1536) Interrogatorio a varios testigos en relación con los pleitos que varios vecinos libraban por entonces en la Real Audiencia y Chancillería de Granada contra el Concejo de Morón de la Frontera. Testimonio de Francisco Hernández de la Plaza: "a la novena pregunta dixo que este testigo a visto e vee que en las alegrías que se an hecho en este pueblo de xlv años a esta parte, que este testigo se acuerda, los toros traen de estas comarcas a la redonda e del término desta villa (...)". 


\section{Propiaterios de ganado lanar (en cabezas de ganado)}

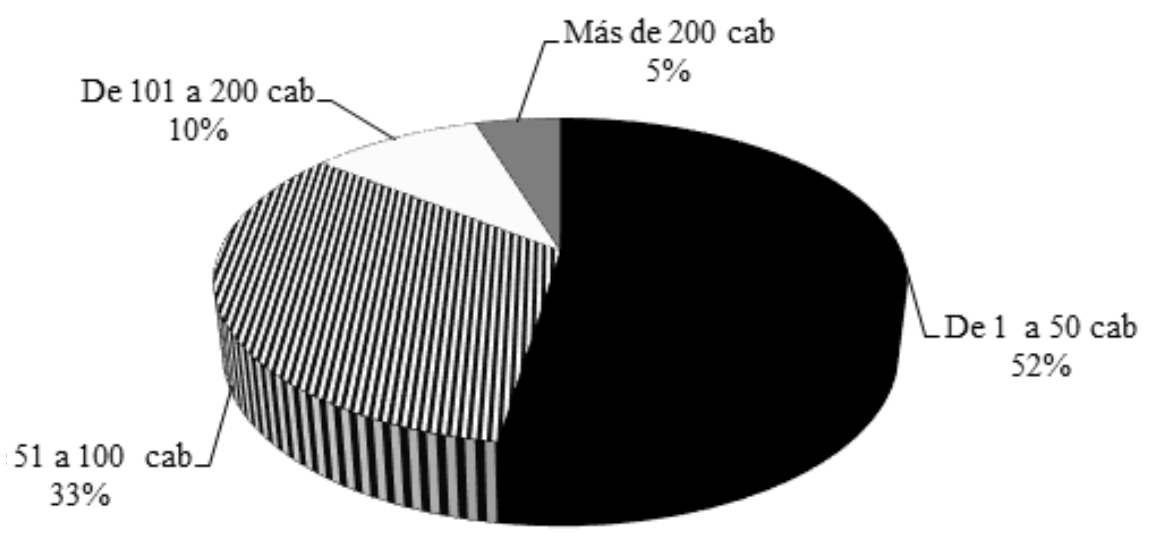

Gráfico 9. Propietarios de ganado lanar. Datos expresados en cabezas de ganado.

especie en la villa. El ganado caprino, con 6.050 ejemplares, fue el más numeroso de cuantas especies ganaderas hubo en Morón de la Frontera, si bien sólo el $9 \%$ de los vecinos de la localidad lo tenía en posesión. Su crianza se realizaba con vistas a la comercialización de materias primas y productos secundarios, y ello pese a que la leche, la carne o el cuero que producían eran de menor calidad que las de otras especies. No obstante, las ventajas que brindaban a sus propietarios eran muy numerosas, de ahí que en época bajomedieval estuviera tan extendida.

De entrada, estos animales tenían una gran habilidad reproductora y sobre todo una excelente capacidad de adaptación, acomodándose a gran variedad de ambientes, situaciones climatológicas y condiciones topográficas. Su punto fuerte radicaba, sin duda, en la facilidad de su alimentación, pues podían adaptarse a entornos con escasos recursos disponibles o aprovechar los forrajes depreciados por otras especies. Sus necesidades espaciales o de transporte tampoco constituían un grave problema y siquiera las pérdidas económicas ante la muerte de un animal eran demasiado graves, sobre todo si la comparamos con otras especies.

En lo que a la concentración de la propiedad respecta, hallamos una distribución bastante equitativa, algo bastante inusual, si bien su rasgo más reseñable es el número tan elevado de propietarios que reunieron cabañas de más de 100 y 200 reses. A modo de balance general, encontramos a un $29 \%$ del total de propietarios que tuvieron entre 1 y 50 animales, un $21 \%$ que contaron entre 51 y 100 , otro $21 \%$ que reunían entre 101 y 200, y el $29 \%$ restante que disfrutaban de más de 200.

El ganado lanar, además de ser una de las especies más numerosas en Morón de la Frontera sólo superada por el ganado caprino, fue la que presentó el porcentaje de concentración más elevado de todo el ganado contabilizado en el año de 1532. Las 4.625 ovejas registradas estaban en manos de un escaso $5 \%$ de la población, en su mayoría pequeños y medianos ganaderos de ámbito local y comarcal que combinaron el autoconsumo con la comercialización de ganado y la 


\section{Propietarios de ganado porcino (en cabezas de ganado)}

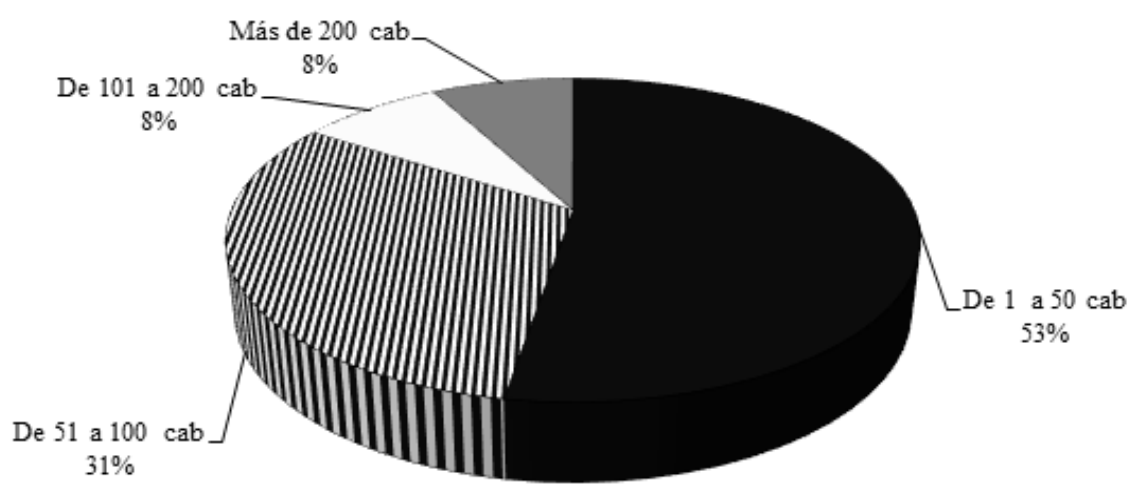

Gráfico 10. Propietarios de ganado porcino. Datos expresados en cabezas de ganado.

producción de materias primas para la industria textil-lana-, alimenticia-leche y carne- y productos secundarios -quesos-.

Si bien estos animales no eran utilidad en el campo en lo que a fuerza motriz se refiere, sí que tras la recogida de las mieses contribuían de forma decisiva al trabajo del hombre mediante la retirada de rastrojos y el abonado de la tierra. Si observamos la concentración de su propiedad, más del $50 \%$ de los pastores locales tenían rebaños de entre 1 y 50 cabezas, el $33 \%$ de 51 a 100, el siguiente $10 \%$ entre 101 y 200 y el $5 \%$ restante más de 200 cabezas. Mención aparte merecen varios propietarios cuyos rebaños representan más del $70 \%$ de la cabaña local.

Y por último, también en la línea de las especies lanar y caprina, se encuentra el ganado porcino, que presentaba un volumen considerable en cuanto a número de ejemplares (3.607 cabezas de ganado) y un nivel de concentración igualmente alto (solo el $10 \%$ del vecindario lo tenía en propiedad, uno de cada diez hogares). Como resultando de ello, en la localidad quedarían conformadas escasas piaras pero muy numerosas en cuanto a volumen, la mayoría orientadas a su comercialización, aunque el autoconsumo contara también con bastante predicamento. En efecto, el cerdo era, de antiguo, el animal de abasto por excelencia y una fuente de materias primas de gran calidad que permitían la elaboración de todo tipo de productos secundarios - carne, grasa y cuero fundamentalmente-. Para conocer su importancia sólo tenemos que ojear brevemente los cuerpos de ordenanzas ganaderas bajomedievales y las continuas referencias que se suceden en las mismas. En el caso de Morón de la Frontera y Arahal, por ejemplo, se llegaron a redactar varios ordenamientos orientados a controlar el acceso a las dehesas e impedir que los frutos de encinas y alcornoques fueran aprovechados con otro fin que no fuera el del propio alimento de estos animales. Respecto a la distribución de la propiedad, un $50 \%$ del total de propietarios dispondría de piaras de entre una y cincuenta cabezas, un $31 \%$ entre 51 y 100 cabezas, un $8 \%$ entre 101 y 200, y finalmente un $8 \%$ de más de 200 cabezas. 


\section{LOS GRANDES GANADEROS LOCALES Y SUS PATRIMONIOS}

Sostenía Borrero Fernández que a inicios de siglo XVI la comarca de la campiña se caracterizó por tener como principal fuente de riqueza la actividad agrícola ${ }^{20}$. Más concretamente, la producción de cereal, que la vestía de extensos campos de trigo y cebada propiedad de la alta nobleza y la Iglesia. Ante el poderío económico de ambas instituciones, los grupos más acaudalados del campo sevillano, las conocidas elites rurales, coparon su espacio y posición basando su hegemonía en otros sectores, principalmente el ganado; no en vano, su cría, reproducción y explotación les era cercana y conocida por haber sido la fórmula tradicional de subsistencia de los habitantes de estas zonas fronterizas desde su incorporación a la corona de Castilla.

Las características del término municipal moronense eran ideales para el desarrollo de la actividad ganadera. Su antiguo alfoz, de amplias dimensiones, disponía de abundantes recursos hídricos y permanecía inculto en su mayor parte. $\mathrm{Su}$ densidad poblacional seguía siendo baja inclusive por entonces, lo que había impedido su roturación y puesta en explotación, y facilitaba el esparcimiento de los animales. La configuración patrimonial de los grandes ganaderos locales marchará en esta dirección. De hecho, el análisis de los padrones municipales, de los inventarios de bienes y de sus cartas de dote muestra que los animales constituyeron su principal elección, alcanzando en torno al $40 \%-50 \%$ del valor total de su patrimonio (en maravedís). En otras palabras, el ganado representaba prácticamente la mitad de sus riquezas familiares, y este índice se muestra incluso superior en algunos casos significativos, llegando a porcentajes del $63 \%$ y $64 \%{ }^{21}$. Asimismo, el tamaño medio de sus cabañas se cifraba en torno a las 450 cabezas de ganado, cuantía considerable no ya por el volumen en sí mismo sino porque sobre un centenar de esas reses eran ganado mayor, vacas y bueyes principalmente, los animales más caros y apreciados en el mercado.

Tuvimos la oportunidad de mencionar ut supra que el ganado menor fue mayoritario en Morón de la Frontera. No obstante, la realidad era que sus especies se concentraban en pocas manos y que su estimación económica era, a pesar de su volumen, reducida. Muestra de ello es que las reses menores se concentraban en las cabañas de apenas seis vecinos. Concretamente, el ganado lanar estaba bajo el control del alcaide Juan Fernández de las Casas, con 2.500 ovejas, de Salvador de Jaraba, líder del bando local de los particulares, con 180, y de la cuantiosa Inés Gutiérrez, apodada como "La Catalana", con 120. En el caso del ganado porcino, nuevamente el alcaide Fernández de las Casas ostentaba el primer puesto del ranking con 800 unidades, seguido por Bartolomé de Humanes con 502 y Alonso de Balbuena con 200. Y para el caprino, el alcalde mayor Pedro González Orellana declaraba poseer 1.300 cabezas, seguido de Martín Fernández Morán con 700 y

20. Borrero Fernández, 2012, pp. 460-461.

21. Sobre los patrimonios de estos miembros de la elite moronense, véanse los anexos que conforman el segundo tomo de mi tesis doctoral. Martín Humanes, 2016, t. II, pág. 183 y ss. 


\section{CONFIGURACIÓN DEL PATRIMONIO DE LAELITE MORONENSE}

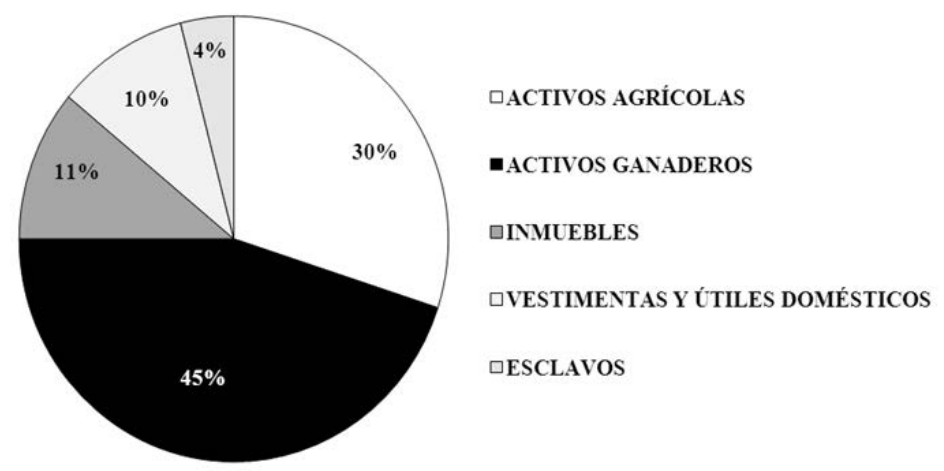

Gráfico 11. Configuración del patrimonio de la elite moronense. Proporciones resultantes de la apreciación y consiguiente monetización de sus bienes muebles e inmuebles en maravedís. Fuentes: Inventarios de bienes.

del alcaide Fernández de las Casas con 25. Esta circunstancia terminaría propiciando que el negocio generado de la producción de materias primas estuviera altamente concentrado y controlado por muy pocos individuos ${ }^{22}$.

Pese a estas cifras, fueron el ganado vacuno y el boyal las variedades que alcanzaron especial protagonismo en el patrimonio de los grandes ganaderos moronenses. Estas reses aparecen siempre en una cuantía muy elevada, lo que da cuenta de la fuerte demanda existente en el mercado sevillano y la importancia que alcanzaron dichas especies a nivel productivo y como fuerza de trabajo. No obstante, a diferencia del Aljarafe o de otras zonas próximas a la capital, la presencia de mercaderes sevillanos en Morón de la Frontera no debió ser muy intensa de acuerdo con los rastros dejados en el archivo de notarías, canalizándose quizás esta demanda a través de los circuitos comerciales provinciales y comarcales que la interconectaban con poblaciones vecinas como Utrera, Alcalá de Guadaira, Marchena, etc. A través de estas localidades y de los agentes comerciales en ellas radicados, activos por toda la región, se adquiría el género moronense que a la postre terminaría distribuyéndose.

Como decía, el gráfico $\mathrm{n}^{\mathrm{0}} 12$ realizado sobre la distribución por especies de las cabañas de los grandes ganaderos locales muestra que la variedad vacuna superó, en la práctica totalidad de los casos, el $60 \%$ del valor total de los activos ganaderos, y que fueron muy habituales casos como los de Juan Fernández Mateos, Hernán Martín de Angulo, Francisco Bohórquez, el alcaide Juan Vázquez Orejón, etc. con valores que llegaron al $96 \%$, 93 \% y $91 \%$ respectivamente. Del $40 \%$ restante, los bueyes constituían en torno al $10 \%$, quedando el $30 \%$ para las especies menores -ganado lanar (12\%), caprino (8\%) y porcino (5\%)-.

22. Una aproximación prosopogáfica a estas figuras en Martín Humanes, 2016, t. II, pág. 229 y ss. 


\section{DISTRIBUCIÓN POR ESPECIES GANADERAS DE LA CABAÑA DE LOS GRANDES PROPIETARIOS MORONENSES. AÑO DE 1532}

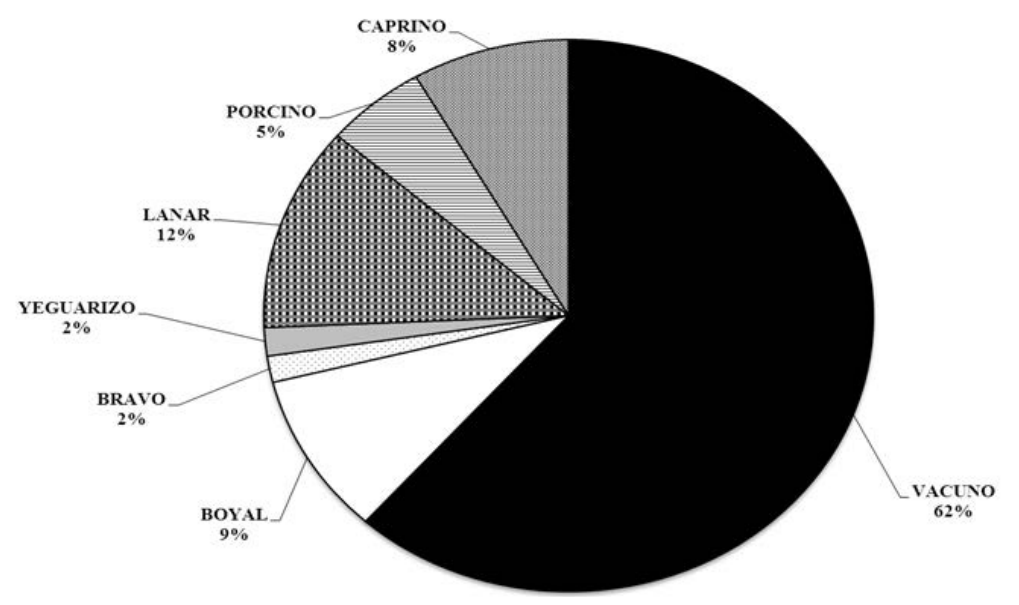

Gráfico 12. Distribución por especies ganaderas de la cabaña de los grandes propietarios moronenses. Datos expresados en cabezas de ganado.

La importancia de este tipo de bienes en general -y del ganado vacuno en particular- entre los altos sectores de la sociedad local se observa también en el protagonismo que sus miembros le concedieron a la hora de diseñar y acometer sus estrategias de reproducción social. En este sentido, he podido documentar como el mismo año de 1532 el mencionado Juan Vázquez Orejón, en las capitulaciones matrimoniales suscritas con el doctor Francisco de Carvajal, de Utrera, para el casamiento de sus hijos Sancha de Osorio y Alonso de Carval, estableció entre las condiciones que daría en dote e casamiento a la dicha mi hija mil ducados de oro en casamiento; las doscientas mil maravedies dellos en ganado vacuno al precio que valiere quando lo diere, (...) las quarenta paridas e el restante a cumplimiento a las dichas dozientas mile maravedies en el dicho ganado vacuno; apreciadas las dichas vacas e ganado por dos terceros señalados e nombrados por ambas partes; (...) y los demás a cumplimiento de los dichos mil ducados en dineros. Francisco de Carvajal, por su parte, ofrecería un perfil distinto de propietario, de clara inclinación agrícola, aportando un quento de maravedis, las ochocientas mil maravedies en heredades en la villa de Utrera que yo señalare, que es en sesenta y cinco arançadas de olivar y en un molino de azeyte e quinze bueyes y en dos esclavos, y el resto en dineros; y asimismo digo que lo que costare la negociación de la exección y libertad del dicho Alonso de Carvajal de no pechar e contribuir que lo pagaré por mi persona e bienes ${ }^{23}$.

23. ANMF, leg. 305, fol. 39v. y 44r. Capitulaciones matrimoniales concertadas entre Juan Vázquez Orejón, alcaide de Morón de la Frontera, y el doctor Francisco de Carvajal, vecino de Utrera, como padres Sancha de Osorio y Alonso de Carvajal. 
Tabla 1. Los grandes propietarios de ganado de Morón de la Frontera y la composición de sus cabañas. Datos expresados en cabezas de ganado.

\begin{tabular}{|c|c|c|c|c|c|c|c|c|c|}
\hline \multirow{3}{*}{ Ganaderos moronenses } & \multirow{3}{*}{$\mathrm{N}^{0}$ cabezas } & \multicolumn{5}{|c|}{ Ganado mayor (cabezas de ganado) } & \multirow{2}{*}{\multicolumn{3}{|c|}{$\begin{array}{c}\text { Ganado menor } \\
\text { (cabezas de ganado) }\end{array}$}} \\
\hline & & \multicolumn{3}{|c|}{ Bovino } & \multirow{2}{*}{$\begin{array}{c}\text { Équido } \\
\text { Yegüerizo }\end{array}$} & \multirow{2}{*}{\begin{tabular}{|c|} 
Híbrido \\
$\begin{array}{c}\text { Mular/ } \\
\text { Asnal }\end{array}$
\end{tabular}} & & & \\
\hline & & Vacuno & Boyal & Bravo & & & Lanar & Porcino & Caprino \\
\hline $\begin{array}{l}\text { Juan Fernández de las } \\
\text { Casas }\end{array}$ & 3.375 & 6 & 39 & 0 & 5 & 0 & 2.500 & 800 & 25 \\
\hline $\begin{array}{l}\text { Pedro González de } \\
\text { Orellana }\end{array}$ & 1.414 & 19 & 52 & 0 & 3 & 0 & 0 & 0 & 1.340 \\
\hline $\begin{array}{l}\text { Martín Fernández } \\
\text { Morán }\end{array}$ & 700 & 0 & 0 & 0 & 0 & 0 & 0 & 0 & 700 \\
\hline Bartolomé de Humanes & 651 & 132 & 15 & 0 & 2 & 0 & 0 & 502 & 0 \\
\hline Salvador de Jaraba & 348 & 107 & 30 & 28 & 3 & 0 & 1.80 & 0 & 0 \\
\hline Alonso de Balbuena & 310 & 67 & 42 & 0 & 1 & 0 & 0 & 200 & 0 \\
\hline Cristóbal de Angulo & 252 & 160 & 18 & 0 & 4 & 0 & 0 & 70 & 0 \\
\hline Antón Romero & 187 & 58 & 27 & 0 & 2 & 0 & 60 & 40 & 0 \\
\hline Juan de Espinal el mozo & 181 & 57 & 28 & 0 & 1 & 0 & 40 & 55 & 0 \\
\hline $\begin{array}{l}\text { Hernán Martín de } \\
\text { Angulo }\end{array}$ & 164 & 115 & 9 & 0 & 0 & 0 & 40 & 0 & 0 \\
\hline Juan de Osuna & 159 & 72 & 18 & 0 & 4 & 0 & 0 & 65 & 0 \\
\hline $\begin{array}{l}\text { Inés Gutiérrez la } \\
\text { Catalana }\end{array}$ & 149 & 117 & 34 & 0 & 3 & 0 & 120 & 0 & 0 \\
\hline Juan Vázquez Orejón & 145 & 124 & 18 & 0 & 3 & 0 & 0 & 0 & 0 \\
\hline $\begin{array}{l}\text { Francisco Jiménez } \\
\text { Parejo }\end{array}$ & 128 & 59 & 45 & 0 & 4 & 0 & 20 & 0 & 0 \\
\hline Juan Fernández Mateos & 115 & 108 & 6 & 0 & 1 & 0 & 0 & 0 & 0 \\
\hline Francisco de Coria & 92 & 66 & 23 & 0 & 3 & 0 & 0 & 0 & 0 \\
\hline $\begin{array}{l}\text { La Catalana de B. } \\
\text { Martín }\end{array}$ & 90 & 71 & 13 & 0 & 1 & 0 & 5 & 0 & 0 \\
\hline Francisco Bohórquez & 87 & 77 & 9 & 0 & 1 & 0 & 0 & 0 & 0 \\
\hline Marina Pérez la Molina & 83 & 56 & 17 & 10 & 0 & 0 & 0 & 0 & 0 \\
\hline Juan Fernández Villalón & 69 & 53 & 27 & 0 & 0 & 0 & 0 & 0 & 0 \\
\hline Total & 8.699 & 1.524 & 470 & 38 & 41 & 0 & 2.965 & 1.732 & 2.065 \\
\hline
\end{tabular}

Sin rechazar totalmente la idea de que la crianza, reproducción y explotación de los rebaños pudo correr cargo de estos grandes propietarios, sobre todo en lo referente al ganado mayor por ser el más productivo, a través de la documentación notarial he podido constatar movimientos del mercado de ganado local en distintos sentidos. No ya de las pequeñas y frecuentes operaciones de compraventa protagonizadas por el conjunto de la población -adquisiciones de pequeña entidad, de una yegua, un buey, un asno, etc.-, sino de arriendos de una parte importante de estas cabañas que parecen indicar la vigencia de prácticas rentistas también en el sector agropecuario. Unos acuerdos, por lo general, de vigencia anual y consistentes en 
cesiones temporales de un elevado número de cabezas de ganado - ganado menor generalmente- que el arrendatario debía regresar una vez vencido el contrato aportando un número de animales sensiblemente superior al recibido; en otras palabras, costeando el trato en especie ${ }^{24}$. De esta manera, los grandes ganaderos moronenses conseguían distintos propósitos: de entrada, descargar sensiblemente el volumen de sus cabañas, máxime en un contexto local de serios problemas de espacios para el ganado. En segundo lugar, incrementar sus activos ganaderos sin necesidad de acometer inversiones, dispendios dinerarios ni asumir riesgos. Y por último, libertad de acción y movimientos para poder atender la situación del resto de sus activos e inversiones. Asimismo, no debemos pasar por el alto la importancia de las redes de relación comercial generadas como consecuencia de estos acuerdos, cuyas conexiones se llegaban a extender al espacio comarcal.

\section{La CAPITULACión DE LAS YERBAS (1519)}

Hace algún tiempo, tras concluir la redacción de la primera entrega del padrón de las yerbas, comencé a preparar esta contribución revisando varios documentos que hablaban de la existencia de una capitulación de la yerba. Me refiero, muy particularmente, a las dispociciones primera y segunda recogidas en el privilegio que el conde viejo concedió en 1478 a Morón de la Frontera y Arahal. Dado que se describían una serie de disposiciones que venían a regular el sistema de tributación y pliego de condiciones para el aprovechamiento de los baldíos señoriales, asumí la existencia de conexiones directas con lo expuesto en el padrón y las informaciones complementarias que manejaba por entonces ${ }^{25}$.

Lastimosamente, no tenía noticias más recientes ni nuevas informaciones al respecto. El Archivo Municipal de Morón de la Frontera no conservaba más evidencias para este período que el antecedente de 1478 y el propio padrón; tampoco guardaba nada el archivo de notarías, por lo que opté por descartar aquel propósito y fijé la vista únicamente en el análisis cuantitativo del padrón. Durante este tiempo, trabajando sobre otros asuntos, volví sobre mis pasos y revisé nuevamente

24. Hemos traído ejemplos de algunos casos. ANMF, leg. 305, f. 127r. (1532). Bartolomé de Humanes arrienda a Marcos Pérez Moreno, vecino de Utrera, setenta y dos puercas por noventa y dos cochinos; ANMF, leg. 305, f. 141r. (1532). Bartolomé de Humanes arrienda a Martín de los Viejos y a Pedro de Morillas, vecino de Marchena, cuarenta puercas por sesenta cochinos; ANMF, leg. 305, f. 293v. (1533) Alonso Jiménez de Osuna arrienda a Bartolomé García Sevillano noventa y dos cabras por sesenta y dos chivas, que debían salir del rebaño arrendado; ANMF, leg. 305, f. 350r. (1533) Cristóbal de Angulo arrienda a Hernán Gutiérrez de Lucernilla y al jurado Juan del Puerto, vecinos de la villa de Marchena, cien puercsas por ciento cinco cochinos; ANMF, leg. 305, f. 385r. (1533) Bartolomé García Sevillano arrienda a Andrés Lobo cuarenta y seis cabras por treinta y una chivas.

25. AMMF, Gobierno, leg. 2, fol. 183v. Privilegio de Juan Téllez Girón, II conde de Ureña, otorgado a la villa de Morón de la Frontera y su aldea del Arahal, concediendo a los concejos de ambas poblaciones, primeramente, el aprovechamiento de las yervas y pastos de todos sus términos, y el cierre de sus montes y cazas en beneficio de los locales, a cambio de treinta mil maravedís anuales. Asimismo, concede a la aldea del Arahal el incremento de regidores y revisa las facultades de sus oficiales en la administración de la justicia. (1478, julio, 21. Morón de la Frontera). 
los papeles manejados para la elaboración de mi tesis doctoral, hoy digitalizados en Pares e insertos dentro de la Colección Osuna del Archivo Histórico Nacional. Sorpresivamente, en ellos pude hallar un documento que respondía a la descripción Copia de las ordenanzas dadas por Juan Téllez-Girón, [II] conde de Ureña y [III señor de Osuna], a los concejos de Morón de la Frontera y Arahal (ambos en Sevilla), sobre la utilización de sus pastos, cuyo traslado estaba fechado en 1528 y su original databa de 1519. Tras su lectura, contextualización y algunas comprobaciones, pude advertir que se trataba de la conocida capitulación de la yerba, que si bien su rastro había desaparecido del catálogo municipal de Morón de la Frontera, todavía se conservaba una copia en el fondo señorial, una de las partes firmantes del acuerdo. Ante esta casual circunstancia, decidí reformular esta segunda entrega y emprender nuevamente su redacción, incluyendo en su fase final el estudio de dicho documento e incorporando su transcripción a modo de anexo ${ }^{26}$.

Aunque ya se ha contextualizado convenientemente tanto el padrón como el acuerdo, no está de más reiterar que la capitulación de las yerbas de Morón de la Frontera venía a sellar un acuerdo entre los concejos de Morón de la Frontera, Arahal y la Casa de Osuna para el arrendamiento de las extensas fincas que la señoría disponía en dichas localidades. El propósito último del mismo era reconducir la política rentista practicada hasta entonces por Juan Téllez Girón, II conde de Ureña, a fin de facilitar que sus pastos no cayeran en manos de ganaderos foráneos y se aprovecharan, previo pago, por los vecinos de ambas localidades, logrando así ubicar a sus ganados y reducir los efectos de la escasez de pastos. Para lograr este propósito proteccionista, los concejos asumieron la iniciativa política y abrieron las conversaciones años antes de la firma definitiva. Con el acuerdo final sellado en septiembre de 1519, las autoridades moronenses y arahalenses lograron su propósito y a su vez no hipotecar la hacienda municipal en ello, pues los compromisos económicos adquiridos los hicieron recaer directamente en sus vecindarios, tras la respectiva elaboración del padrón y su repartimiento.

Son un total de nueve cláusulas bien definidas las que conforman la capitulación de la yerba. Se trata, por demás, de un documento singular y bastante especial en su tipología. La pieza conservada, elaborada en Osuna, es una especie de borrador negociador, bastante definido y avanzado en sus términos, que los regidores de Morón de la Frontera y Arahal hicieron llegar al Conde Viejo y que éste, con el asesoramiento de sus letrados, va a ir ajustando, glosando, matizando en sus numerosos flecos y, en última instancia, aprobando. Capítulo a capítulo.

La primera de estas nueve disposiciones proponía definir el marco general del acuerdo. Para ello, Morón de la Frontera y Arahal ofrecían a Juan Téllez Girón una cuantía de 50.000 maravedís anuales a pagar por la tenencia exclusiva de sus campos en el señorío moronense ${ }^{27}$. A fin de evitar abusos tanto en el régimen de explotación como en el uso y disfrute de las fincas, las villas plantearon la aplicación

26. El texto en cuestión se recoge en el tomo II de mi tesis doctoral. Vid. Martín Humanes, 2016, vol. II, pág. 65 .

27. Nunca fue una cuantía equitativa sino a sufragar en función del total de las reses que presentaba anualmente cada población. 
de dos medidas: por un lado, la prohibición expresa de cualquier subarriendo de los terrenos y, por otro, la negativa a introducir en ellos animales que no fueran propiedad de los vecinos. En relación con esta segunda pauta, las autoridades locales recogieron una excepción que indicaba que sí serían aceptadas y admitidas especies tenidas a renta por los vecinos; concretamente, puercos, ovejas y cabras para criar, bueyes de arada y yeguas de trilla.

En términos generales, el Conde Viejo aprobó los lineamientos del primero de los puntos, aunque los reformuló en algunos de sus aspectos. Salvado el escollo del montante total anual, el punto más llamativo fue el de la periodicidad del acuerdo. Lejos de establecer un plazo de tiempo que brindara estabilidad, seguridad y certidumbre a la cabaña local y a sus propietarios, la señoría prefirió no contraer compromiso temporal alguno -el tiempo que mi voluntad fuere que lo tengáis-, de ahí que la vigencia de la capitulación y su renovación quedara sometida a su entera voluntad, pudiendo extinguir unilateralmente el acuerdo sin tener que afrontar reparos a la otra parte ni a terceros. Asimismo, sus letrados impusieron que la nueva capitulación respetara los arrendamientos de las dehesas y donadíos que el conde había suscrito anteriormente de forma privada, y que por entonces se encontraban en vigor. Dichas tierras debían quedar en las mismas condiciones de uso y disfrute acordadas con sus tenedores durante los años estipulados, y así se mantendrían hasta el momento de la expiración del contrato, sumándose entonces a la bolsa general de tierras arrendadas, sin sobrecoste. También ajustó las condiciones iniciales propuestas para la entrada de ganado. La señoría modificó el criterio de los concejos y determinó que ningún vecino ni persona estante en la villa pudiera introducir en ellas ganado tenido a renta, a excepción solo de yeguas de trilla y bueyes de arada, y siempre a proporción del caudal de su propietario o al aumento de labor. En relación con las demás especies arrendadas, la señoría las dejaba fuera del acuerdo y sancionaba con la pérdida de los animales en caso de ir contra lo dispuesto.

El segundo de los capítulos buscaba definir cómo afectaría el nuevo acuerdo a la situación de los albarranes presentes en el señorío ${ }^{28}$. Muy particularmente, las autoridades de ambas localidades planteaban si éstos debían ser considerados en el aprovechamiento de las tierras disponibles para pasto y, en caso de que así fuera, en qué condiciones y qué obligaciones contraían éstos como beneficiarios. En la redacción final de la propuesta elevada a la señoría, ambos concejos reconocieron el papel que los albarranes venían desempeñando en sus poblaciones, sirviendo a sus vecinos y moradores en la reproducción y crianza de sus animales. Por ésta y otras razones, plantearon que tanto los albarranes presentes como los futuros fueran considerados en el aprovechamiento de la yerba pagando para ello sus correspondientes derechos, y que rezando como tal se pudiera traer o tener en el campo hasta treinta cabezas de ganado menor, siempre que fueran puercos, ovejas, cabras o carneros, y hasta diez cabezas de ganado mayor. La medida logró la aprobación

28. Voz albarrán: "el soltero, el que no tiene domicilio, casa, ni hogar: el que se anda a sus aventuras, el forastero". COVARRUBIAS, S., Tesoro de la lengua castellana, o española. Madrid, 1611 , t. I, fol. 32v. 
de Juan Téllez Girón, quien previo a su sanción añadió una disposición aclaratoria indicando que el albarrán que la cuantía de ganado rebasase fuera penado y quitado del campo como ganado que no ha a dentrar conforme a las ordenanzas que yo tengo mandadas sobre esto ${ }^{29}$.

La disposición tercera del acuerdo estudiaba cómo se deberían llevar a cabo las preceptivas tareas de control y vigilancia de estos campos. Para ello, se hacía preciso determinar el rol que jugarían en adelante las autoridades locales sobre unos pagos que seguían siendo privados, propiedad del conde viejo, pero que adelante serían administrados por ambas poblaciones. La propuesta elevada a la señoría planteaba que la Casa de Osuna conservase los oficiales que por entonces dedicaba a estas labores, a los cuales se les sumarían en adelante más efectivos: por un lado, los dos mayordomos del campo de los que ya disponía Morón de la Frontera para sus tareas cotidianas; y por otro, otros dos oficiales aportados por la aldea del Arahal, si bien su regimiento no contaba todavía con dichos oficiales en plantilla. Para establecer la equiparación de cargos entre las dos poblaciones, se solicitó a Juan Téllez Girón la concesión de licencia para el nombramiento ad hoc de dos mayordomos de campo arahalenses de igual naturaleza y atribuciones que los de la villa matriz, y cuyos salarios se abonarían por los propios de la hacienda aldeana. En sintonía con lo expuesto, el conde procedería al nombramiento de dos nuevos mayordomos de campo para la aldea y, acto seguido, a la aprobación de la medida.

El punto cuarto trataba específicamente sobre el desempeño de los mayordomos de campo. En el mismo se buscaba fijar cómo debían asignarse las cuantías recaudadas por las penas dinerarias procedentes de la comisión de infracciones vecinales. En este sentido, Morón de la Frontera y Arahal planteaban que las penas tomadas por sus oficiales fueran a parar a las arcas de la población respectiva, y que solo en caso de intervención conjunta de los mayordomos el montante se dividiera a partes iguales, siguiendo los usos y costumbres locales. Al tratarse de una materia interna que afectaba en exclusiva a los concejos, a los oficiales locales y al reparto de la recaudación, la señoría aprobó la propuesta sin ninguna objeción. No obstante, sí añadiría que en caso de que sus arrendadores de tierras se viesen agraviados a cuenta de lo establecido en dichos capítulos sobre los mayordomos de campo, que ellos tuvieran la posibilidad de acudir ante mí (...) e mostrar, que yo les mandaré oyr e guardar su justiçia. Igual parecer mostró ante la propuesta recogida en el título siguiente, el capítulo quinto, y por la cual villa y aldea declaraban que lo recaudado en multas por este concepto sería destinado estrictamente a cubrir el pago de la renta de la yerba, el cual debían afrontar, por separado, anualmente, ambos concejos. Con esta medida, ambas instituciones se veían favorecidas económicamente a la hora de afrontar el pago haciendo del mismo una carga más liviana, al tiempo que las movía a buscar para dichos cargos a personas

29. Sobre este particular véase lo dispuesto en el privilegio de Juan Téllez Girón, II conde de Ureña, otorgado a la villa de Morón de la Frontera y su aldea del Arahal concediendo a los concejos de ambas poblaciones el aprovechamiento de las yervas y pastos de todos sus términos, y el cierre de sus montes y cazas en beneficio de los locales, a cambio de treinta mil maravedís anuales. (1478, julio, 21. Morón de la Frontera). AMMF, Gobierno, leg. 2, fol. 183v. 
competentes y capaces que actuaran como buenos mayordomos e diligentes por ser aprovechados, evitando fraudes y otras prácticas.

En el capítulo sexto las autoridades de Morón de la Frontera y Arahal proponían hacer extensiva a estos pagos la normativa municipal sobre la saca de cosas $v_{\text {vedadas }}{ }^{30}$. En virtud de la misma, a los vecinos con ganado les quedaba prohibido sacar de sus confines toda caña, madera, esparto y palmito que hallasen, y arrogarse la concesión de licencias para ello que acostumbraban a dar a foráneos, bajo severas sanciones. El segundo conde de Ureña refrendó la aplicación de esta medida añadiendo que la pena impuesta a quien estos delitos cometiesen fuera de 3.000 maravedís destinados a su hacienda, y no a los concejos, y que en caso de insolvencia el reo recibiera 100 azotes y fuera desterrado a perpetuidad de ambas poblaciones.

En el séptimo capítulo los concejos de Morón de la Frontera y Arahal solicitan al conde pagar la renta anual de los 50.000 maravedís, junto a sus vecinos, el día de San Miguel (29 de septiembre) e no antes, y que para ello pedían se informase al mayordomo y recaudador señorial, para que sabiéndolo no los solicite antes de lo convenido, a lo que la señoría accede y notifica a su oficial que proceda en tales términos.

Con idea de establecer un sistema de tributación proporcional y acorde al valor de mercado de los animales, en el octavo capítulo los concejos de Morón de la Frontera y Arahal propusieron a la señoría elaborar el repartimiento de la yerba convirtiendo todo el ganado tributario en vacas, de tal manera que dos bueyes paguen por vna vaca, porque andan en dehesas, e diez ovejas, e diez cabras, o diez carneros, o diez puercos o puercas, o diez cochinos por vna vaca (...) e que cada vna yegua por vna vaca, e que los cochynos e corderos se an de contar diez por vna vaca. Tras designar al ganado vacuno como la unidad de referencia-unidad ganadera-, se solicita que en dicho recuento solo computen las reses nacidas antes del día de San Juan de cada año (23 de junio). Nuevamente, al tratarse de cuestiones físcales que los concejos establecían con sus vecinos y sin más repercusión para los intereses de la Casa de Osuna, el Conde Viejo aprobó íntegramente lo dispuesto en la cláusula.

En el noveno y último punto de la capitulación los concejos van a tratar de perfilar varios cabos sueltos del sistema de tributación vecinal. Concretamente, su intención va a ser la de fijar las cargas que debía afrontar el ganado que habiendo disfrutado de los pastos se veía inmerso en operaciones de compraventa, cambios de titularidad y cese del disfrute. En relación con estas cuestiones, las autoridades locales manifiestan su intención de considerar como ganado sometido a tributación todo animal tenido por vecinos y moradores de la villa desde el día de año nuevo en adelante, y que aunque fuesen vendidos antes del día de San Juan sus anteriores dueños debían pagar por ellos como si aún los mantuviesen. Sí podían quedar exentos del tributo los vendedores en caso de que fuese el comprador quien pagase la yerba, siendo vecino o morador y estando el ganado en los pagos

30. Vid. las referencias a este particular en AMMF, Gobierno, leg. 2, fol. $183 \mathrm{v}$. 
señoriales. En caso contrario, de ser foráneo o no llevar su ganado a estos predios, debía ser el vendedor definitivamente quien hiciera frente al tributo. En esta ocasión, sí habrá pronunciamiento señorial al respecto, manifestando, en efecto, que el vendedor pagase por el tiempo que disfrutó de la yerba y que éste declarase el nombre a quién vendió las reses, a efectos de posible cobro. Asimismo, establecía que el comprador que hubiera comido de la yerba pagase por el tiempo y según cuanto comiere, siendo justicia que aunque no goze de la yerba, que pague.

A modo de cierre, Juan Téllez Girón incorporaría un colofón en el que estipuló que en caso de contravenir lo dispuesto por la capitulación, los concejos fuesen penados con 20.000 maravedís en favor de la hacienda señorial, los particulares con 2.000 maravedís y que el resto de las penas fijadas por las ordenanzas locales se doblaran en caso de cometerse las infracciones en estos campos.

\section{CONCLuSiones}

El presente estudio viene a confirmar la importancia de la ganadería como actividad económica esencial entre los habitantes del señorío de Morón de la Frontera y su entorno a inicios de s. XVI. Asimismo, los datos e informaciones expuestos revelan el impacto decisivo que tuvo la explotación de los recursos naturales locales y más inmediatos en el sostenimiento y pervivencia de sus vecinos. El planteamiento que he tratado de ofrecer señala también la problemática en torno a la distribución de la propiedad de la tierra en estas villas y lugares, así como el papel dominador que en ellas ejercieron instituciones como la alta nobleza en su condición de propietarios y arrendadores de extensas fincas. Ello me ha llevado, y debe seguir haciéndolo, a preguntarme sobre la conflictividad cotidiana inherente a esta actividad económica en los planos local, comarcal y regional hispalense, así como sobre sus numerosas implicaciones.

En este sentido, el contexto que mueve a la elaboración de las fuentes estudiadas muestra la consolidación de dos fenómenos simultáneos y que por entonces comprometían el desarrollo de la actividad ganadera: la escasez de pasto y la cada vez mayor densidad animal que soportaban los espacios pastoriles habilitados. De ello se proyecta y dibuja una lucha feroz por la tenencia y disfrute de los lugares de pasto entre diversos agentes, que provocará cambios relevantes en las formas de explotación del campo y con ello el desplazamiento de cabañas foráneas hacia los territorios de la Banda Morisca. Una disputa, dicho sea de paso, abierta y resuelta por el mismo cauce: el económico.

A lo largo de estas páginas se ha presentado también al señorío de Morón de la Frontera como un enclave natural de primer orden en la región, se han descrito los atractivos que ofrecía su alfoz histórico así como los factores que hicieron que sus pobladores se emplearan en el ganado y que foráneos vieran a la villa como un lugar óptimo para la reproducción, crianza y desarrollo de sus cabañas. Pueden contrastar estas afirmaciones con las cuantías de ganado que ofrecen las ilustraciones 2 y 3 del texto de 2017, en donde se muestra la recaudación en menudos de esta 
villa y sus localidades aledañas. No obstante, las respuestas a estas aparentes discrepancias pueden estar en la naturaleza de los datos ofrecidos, en los que habría que considerar los acuerdos tributarios en tornos a diezmos y otros tributos que la iglesia sevillana mantenía con los señores de la zona todavía a inicios de s. XVI; y asimismo, la consideración de que la recaudación tributaria del cabildo catedral sobre un conjunto de poblaciones nada tenía que ver con la densidad ganadera de un determinado territorio, máxime si las cabañas procedían de otros territorios y solo pastaban en la localidad por temporadas.

El estudio de las cifras del padrón de la yerba ha revelado que fisonomía de la cabaña ganadera moronense se cuantificaba en 18.700 animales, con predominio numérico del ganado menor sobre el ganado mayor (74\%-26 \%); cifras acordes a lo expuesto por anteriores investigaciones sobre el conjunto de la comarca campiñesca sevillana. La especie más numerosa fue la caprina (32\%), seguida de la lanar $(23 \%)$, porcina $(19 \%)$, vacuna $(14 \%)$, boyal $(11 \%)$ y yegüeriza $(1 \%)$. Pese a todo, tal y como se ha comentado a lo largo del estudio, las cifras expuestas no pueden tomarse como absolutas para esta población, debiendo ser matizadas y precisadas de acuerdo a la tipología de especies que contempla la capitulación.

La renta de la yerba, fijada en 50.000 maravedís anuales, recayó sobre los vecinos de las localidades de Morón de la Frontera y Arahal que llevaron sus reses a los baldíos propiedad de los Téllez Girón. El pago correspondiente a cada población nunca fue equitativo. Éste dependió del número de animales que figuraban en los padrones anuales elaborados a tal efecto por las poblaciones, fijándose así la proporción a pagar por los vecinos de cada una de ellas. En 1532, Morón de la Frontera debió hacer frente al pago de 20.240 maravedís por 31.684 maravedís de Arahal.

Para la estipulación del pago por vecino se empleó un sistema de conversión de especies a unidades ganaderas, tomando a la vaca como unidad de referencia. Se han aportado numerosos testimonios que describen con detalle dicho procedimiento. En Morón de la Frontera, el año de 1532 resultaron algo más de 5.000 unidades ganaderas, con claro predominio del ganado mayor sobre el menor (72 \%-28 \%), de ahí que el peso de la tributación recayera sobre vacas, bueyes y yeguas.

La distribución de la propiedad del ganado sobre el vecindario moronés fue muy desigual y poco equitativa, especialmente en lo que respecta a los segmentos populares y de bajos recursos. Ya en cotas más elevadas se observa una amplia diversidad en lo que respecta a la tenencia de las distintas especies, generando muy diversos tipos de propietarios en relación con prácticas de autoabastecimiento, alquileres de animales como fuerza de trabajo o comercialización de materias primas.

Las elites locales han sido también parte de mi análisis. Éstas tuvieron una fuerte presencia en la actividad ganadera moronense. De hecho, dominaron todas las facetas del sector llegando a acaparar casi el $50 \%$ de las cabezas de ganado existentes en la villa. El control ejercido sobre este sector productivo se constata incluso en los ordenamientos de tipo económico o en la regulación del espacio natural redactada por las autoridades concejiles. En todos ellos se manifiestan como un grupo de poder fáctico e influyente que participa en las deliberaciones de los cabildo y hace prevalecer sus criterios e intereses por encima del de los 
demás colectivos. Asimismo, sus inventarios de bienes revelan que los animales fueron también el activo con mayor presencia y valoración en sus patrimonios, por encima incluso de los bienes inmuebles. Sobre todas las especies destacaron especialmente las reses vacunas, llegando a jugar un papel clave en sus estrategias de reproducción y ascenso social.

La documentación señala a Juan Téllez Girón, II conde de Ureña, como verdadero impulsor de la explotación sistemática de sus fincas en la localidad, defensor del acuerdo entre partes en favor de la prosperidad de sus vasallos y feudos, y de la búsqueda prioritaria del rédito económico para las arcas señoriales. No he podido determinar por qué razones se extinguieron los acuerdos de 1478, antecedentes de la capitulación de 1519. Lo que sí se he podido constatar ha sido que el Conde Viejo, tiempo después de su firma, los dejó sin efecto y apostó por la fórmula de arrendadores foráneos que se mantuvieron presentes en este territorio hasta fines de la segunda década del s. XVI.

La elaboración del padrón y la consiguiente firma de la capitulación también avalan el dinamismo y la iniciativa política que mostraron villas y aldeas ante circunstancias de este tipo. Todo ello apoya e impulsa la idea de un mundo rural medieval y moderno entendido también como espacio político de acuerdo, conflicto y negociación, que se amplía más allá de los límites de villas y lugares y en donde iniciativas eran compartidas y desarrolladas de manera tanto individual como colectiva por sus principales instituciones de gobierno (poderes señoriales, villanos y aldeanos actuando simultáneamente en favor de la idea del bien común).

Puede suscribirse igualmente que el derecho, la normatividad local y las relaciones contractuales entre las partes fueron la herramienta básica empleada en el desarrollo de estos marcos colaborativos existentes en el mundo rural, del mismo modo que fueron las ideas comunes de prosperidad, rédito económico y enriquecimiento, tanto presente como futuro, las que hicieron prosperar la capitulación de las yerbas de 1519 .

\section{APÉNDICE DOCUMENTAL}

1519, septiembre, 2. Osuna.

Ordenanzas sobre la yerba y la explotación del campo de Morón y El Arahal, otorgadas por Juan Téllez Girón, II conde de Ureña.

AHN, Osuna, C. 3434, D. 24.

B.- Traslado autorizado realizado en Morón de la Frontera el 5 de octubre de 1528, por Francisco Vázquez, escribano público y del concejo de Morón de la Frontera. Buen estado de conservación. Escritura cortesana.

${ }^{/ /}{ }_{1 \mathrm{r}}^{31}$ Yo, don Juan Téllez Girón, conde de Urena etc., vi vuestra petiçión de vos, los conçejos, alcaldes, regidores de mys villas de Morón y del Arahal, e çiertos capítulos de la orden que distes ambos conçejos para la guarda del canpo e yerva de las dichas villas de

31. Al margen izquierdo: Ordenansas sobre el pasto y yervas. 
que yos hize merçed, de vos la mandar dar por çiquenta myle maravedís en cada vn año, por el tienpo que my voluntad fuere que la tengays, por la qual dicha petiçión e capítulos me pedís e suplicáis que los confirme e aprueve, o aquello que más servido fuere, e provea en ello lo que más sea a my serviçio, lo que todo por my visto e platicado con mys letrados a los dichos capítulos e a cada vno dellos por sy, mandando e horden e forma que en ellos avéys de tener en la manera siguiente.

En este primero capítulo que dezís que yos dé el canpo çerrado, de manera que yo no mande arrendar el canpo en poca ny en mucha cantidad, e tanpoco los vezinos, conçejo ny alcaldes, ny otra persona nynguna pueda meter en el dicho canpo nyngún ganado que sea suyo, en poco nyn mucho, por ninguna manera, salvo sy no fuere puercos, o obejas, o cabras a renta para criar, o bueyes de renta o yeguas de trilla para trillar.

An quanto a este capítulo, que yo e por bien de vos fazer merçed e dar e doy $/ /{ }_{1 v}$ el dicho canpo çerrado por el tienpo que mi voluntad fuere que lo tengays por el preçio arriba declarado que me aveys de dar e pagar en cada vn año, e que yo nunca daré a renta el dicho canpo en poca ny en mucha cantid $3,81 \mathrm{~d}$, eçebto que los arrendamientos questán hechos e se hazen de mys dehesas e algunos donadíos, questos los arrendadores dellos vsen commo hasta quí an vsado, e commo quando yo mandava arrendar el dicho canpo e yerva e (a) arrendadores particulares, e que nyngún vezino ni estante en estas villas no pueda meter otro ganado por arrendamiento salvo las yeguas que obiere menester para trillar, e los bueyes que ovieren menester para arar, a proporçión de su cabdal o de aumento de lavor, e no otro ganado nynguno de puercas ny ovejas ny cabras a renta, e si las metieren, que lo ayan perdido, e asímismo que en quanto al ganado que pueda meter my arrendador del Arahal que hasta que pase este arrendamiento questá fecho lo pueda meter tanto e según que hasta aquí se a fecho e cunplido el dicho arrendamiento, my voluntad es quel dicho arrendador non pueda meter ningún ganado de fuera parte.

Yten, el segundo capítulo dezís que los albarranes questuvieren en cada vna desas villas o vinyeren a bivir o asentar su vida en ellas, $/ / 2 \mathrm{r}$ puedan traer e tener en el dicho canpo hasta treynta cabeças de ganado menor que sean puercos, o ovejas, o cabras, o carneros, e de ganado mayor fasta diez cabeças, porque los vezinos e moradores puedan fallar e fallen quyen mejor les puedan servir pagando los tales albarranes la yerva que les cupiere como los ganados de sus villas.

A este capítulo digo questá bien asy commo lo dezís, e mando que asy se haga, en tanto quel albarrán que más ganado desto metiere sea penado e quyntado (sic) del canpo commo ganado que no a dentrar en el canpo conforme a las hordenanças que yo tengo mandadas dar sobresto.

Yten, el terçero capítulo dezís que yo tenga la guarda del canpo como me la tengo, e que vos el conçejo de Morón tengays vuestros dos mayordomos del canpo como os los teneys, por merced mía, e que yo dé liçençia a vos el dicho conçejo del Arahal para que podays poner otros dos mayordomos para la guarda de dicho canpo, e os mande dar liçençia para que les deys salario de los propios del conçejo commo haze el conçejo de Morón a los que pone.

32. En el encabezamiento de la foja. Parte izquierda: ordenanças de la yerva. Parte derecha: padrón de la yerva. 
A este capítulo digo que se faga ansí commo lo pedís, e por esta my carta doy liçençia al dicho conçejo de la villa del Arahal para que pueda poner otros dos mayordomos del canpo como tiene el conçejo de Morón, // $2 \mathrm{v}$ e mando que les paguen de los propios del conçejo lo que ansí obieren de aver por su trabajo otro tanto e según e en la manera quel conçejo de Morón da a sus mayordomos, e quel mayordomo del conçejo del Arahal qués agora pague la librança quel conçejo hiziere del salario destos mayordomos, no ostante otra provisión que sobresto yo e mandado dar.

En el quynto (sic) capítulo dezís que las penas que tomaren los mayordomos de Morón sea para el conçejo de Morón, e las penas que tomaren los mayordomos del Arahal sea para el conçejo del Arahal, con tanto que sy los mayordomos de los conçejos o qualquier dellos se hallaren juntos con mis guardas en tomar alguna pena o penas, las partan por medio como fasta agora las an pasado las dichas guardas e los mayordomos de Morón, questa mysma hordenança aya e se tenga entre los mayordomos de vn conçejo e los (tachado: de) otros de otro quando se hallaren juntos al tomar de las penas.

Que se faga asy como lo pedís, e que asy está bien, pero mando que si alguna cosa de lo contenydo en este capítulo o en alguno de los otros capítulos mys arrendadores desas mys villas se sintieren agraviados, que parezcan ante mí a lo dicho e mostrar que yo les mandaré oyr e guardar su justiçia.

$/ /{ }_{3 \mathrm{r}}$ En el quynto capítulo dezís que las penas que tomaren estos mayordomos de los ganados anexos a la yerva, questas cada mayordomo acuda con ellas a su conçejo para ayuda a pagar la yerva que les cupiere, por manera que las personas que tomaren de yerva los mayordomos del Arahal no tengan parte en ella los vezinos de Morón, ny los que tomaren los mayordomos de Morón no tengan parte en ellas los vezinos del Arahal, salvo que cada conçejo se aproveche de las suyas para ayuda a pagar su yerva. Y esto es bien que sea asy, porque cada conçejo tenga cuydado de poner buenos mayordomos e diligentes por ser aprovechados.

Que se haga así commo lo pedís en este capítulo, e asy mando que se cunpla e guarde.

En el sesto capítulo dezís que los vezinos e moradores desas villas no puedan sacar ny llebar desas villas ny de sus témynos caña, ny madera, ny esparto, ny palmitos ny otra cosa nynguna, ny dar liçençia a persona nynguna forastero para que lo saque a fuera parte más de commo hasta agora lo podían fazer, e so aquellas penas que solían tener e tenían las personas que la sacavan e llevavan sin liçençya o quyen la solía dar e podía.

En quanto a este capítulo mando que ay se guarde e cunpla, // e que la persona que alguna de las susodichas cosas sacare fuera del térmyno de las dichas villas yncurra en pena de tres myle maravedís para mi cámara e questa pena le sea luego llevada y executada, y el que no tuvierede que la pagar le sean dados çien açotes e sea desterrado perpetuamente de las dichas villas.

Et en el sétimo capítulo dezís que los çincuenta myle maravedís que vos los dichos conçejos e vezinos de las dichas villas me aveys de pagar en cada vn año que los querays pagar todos juntos el día de San Myguel de cada vn año como lo pedís, e por esta my carta mando a my mayordomo e recabdador mayor que tovieren cargo de cobrar los dichos maravedís que al dicho plazo cobren los dichos çinquenta myle maravedís e no antes. 
Et en quanto a este capítulo digo que yo he e por bien por vos fazer merçed questos çinquenta myle maravedís pagueys todos juntos el día de San Myguel de cada vn año commo lo pedís, e por esta my carta mando a my mayordomo e recabdador mayor que tovieren cargo de cobrar los dichos maravedís que al dicho plazo cobre los dichos çinquenta myle maravedís e non antes.

Et en el otavo capítulo dezís que la orden que days los ofiçiales de anbas villas quel repartimyento $/{ }_{4 \mathrm{r}}$ de los dichos çinquenta myle maravedís que me aveys de dar e pagar la dicha yerva es que todo el ganado se faga vacas, de tal manera que dos bueyes paguen por vna vaca, porque andan en dehesas, e diez ovejas, e diez cabras, o diez carneros, o diez puercos o puercas, o diez cochinos por vna vaca, e desta manera se repartan por cantidad lo que cada vno toviere, e que cada vna yegua por vna vaca, e que los cochynos e corderos se an de contar diez por vna vaca, e que an de ser todos los que estuvieren naçidos por San Juan de junyo de cada año.

Questá bien asy como lo pedís, e asy mando que se cunpla e guarde.

Et en el noveno capítulo dezís que qualesquyer ganados que tuvieren qualesquyer vezynos e moradores de ano nuevo en adelante, en cada vn año, que avnque los vendan antes de San Juan que pague por ella o de la persona que los tiene para que pague la dicha yerva sy fuere vezyno o morador y estuviere en el canpo, porque sy fuere forastero o no estoviere en el dicho canpo pagara por ello el que los vendiere como dicho es.

En quanto a este capítulo, mando quel vendedor pague por el tienpo que gozó de la yerva, e por en lo de adelante que diga e nonbre a quién lo vendió, e si el conprador lo obiere comydo de la dicha yerva que lo pague en el tienpo e según que comyere, y en lo demás en el dicho capítulo contenydo es justiçia que no gozando de la dicha yerva lo pague.

$/ /_{4 \mathrm{v}}$ En esta manera e según va declarado e respondido de suso a cada capítulo mando que se cunpla e guarde, e que anbos conçejos e vezynos e moradores dellos de las dichas mis villas de Morón y El Arahal, de vna conformidad, lo tengays e guardeys e cumplays asy, so pena de veynte myle maravedís a cada conçejo que contra ello fuere, e si fuere persona particular dos myle maravedís para my cámara, e porque mejor se guarde e cunpla mando que las penas que se an de llevar a los ganados e dueños dellos que contra lo susodicho hizieren sean dobladas de lo que hasta aquí solían llevar, e que asy lo declareys e mandeys en vuestros conçejos.

Fecho en la villa de Osuna, dos días del mes de setienbre de myle e quinientos e diez e nueve años. El conde, mi señor. Ribera.

\section{BibLiografíA}

Andreolli, Bruno (2001-2002), "L'uso del bosco e degli incolti”, Pinto, Giuliano, Poni, Carlo, Tucci, Ugo (A cura di), Storia dell'agricoltura italiana. Il medioevo e l'età moderna, Firenze: Accademia dei Georgofili, 123-144.

Argente Del Castillo Ocaña, Carmen (1991), La ganadería medieval andaluza. Siglos XIII-XVI (reinos de Jaén y Córdoba), 2 vols., Jaén: Diputación. 
Borrero Fernández, Mercedes (2012), "Elites rurales y mercado en la Andalucía Bajomedieval", en Pautes de consum i nivells de vida al món rural medieval. Publicacions de la Universitat de València, pp. 445-467.

Cabrera Muñoz, Emilio (2002), "El bosque, el monte y su aprovechamiento en la España del sur durante la Baja Edad Media", Pérez-Embid, Javier (ed.), Andalucía Medieval. Actas I Jornadas de Historia Rural y Medio Ambiente. (Almonte, 23-25 mayo 2000), Huelva: Universidad, pp. 249-272.

Carmona Ruiz, María Antonia (1995), La ganadería en el Reino de Sevilla durante la baja edad media. Sevilla.

Carmona Ruiz, María Antonia (1996), "La actividad ganadera en la Banda Morisca", en Actas de las II Jornadas de Temas Moronenses. La Banda Morisca durante los siglos XIII, XIV y XV (17 al 20 de octubre de 1994). Sevilla, pp. 157-173.

Carmona Ruiz, María Antonia (1997a), "La ganadería en Carmona durante la Baja Edad Media", en Archivo hispalense: Revista histórica, literaria y artística, Tomo 80, $\mathrm{n}^{\circ}$ 243-245, (Ejemplar dedicado a: I Congreso de Historia de Carmona: Edad Media. Actas), pp. 283-326.

Carmona Ruiz, María Antonia (1997b), "Los aprovechamientos interconcejiles de Tierras comunales: la Hermandad de Pastos entre Marchena, Morón, Arahal y la Puebla de Cazalla de 1501", en Actas de las II Jornadas Sobre Historia de Marchena. Marchena Bajo los Ponce de León. Marchena, Ayuntamiento de Marchena, pp. 123-140.

Carmona Ruiz, María Antonia (2000a), "El aprovechamiento de la Algaida de Cote (Bosque de San Pablo, Montellano) ss. XIII-XVI”, en Apuntes 2: Apuntes y Documentos para una Historia de Osuna, 3, pp. 29-58.

Carmona Ruiz, María Antonia (2000b), "Las relaciones agricultura-ganadería en la Reglamentación Concejil Tardomedieval. Las ordenanzas de El Arahal”, en La Andalucía medieval: actas "I Jornadas de Historia Rural y Medio Ambiente”. Almonte, pp. 345-354.

Carmona Ruiz, María Antonia (2001), "Volumen y distribución de la cabaña ganadera en el Reino de Sevilla: Finales del XV-Principios del XVI", en Historia. Instituciones. Documentos, 28, pp. 31-89.

Carmona Ruiz, María Antonia (2009), "Ganadería y frontera: los aprovechamientos pastoriles en la frontera entre los reinos de Sevilla y Granada. Siglos XIII al XV", En la España medieval, 32, pp. 249-272.

Carmona Ruiz, María Antonia (2011), "La villa de Arahal en el contexto de las actividades ganaderas en la Banda Morisca", en Archivo hispalense, 94, $\mathrm{n}^{\circ}$. 285-287, pp. 17-49.

Carmona Ruiz, María Antonia (2014), "Las actividades pastoriles en Jerez de la Frontera: siglos XIII-XIV”, en Manuel Antonio Barea Rodríguez y Manuel Romero Bejarano (coords.); José Sánchez Herrero y Manuel González Jiménez (dirs.) 750 aniversario de la incorporación de Jerez a la Corona de Castilla: 1264-2014, pp. 195-219. 
Clemente Ramos, Julián (ed.) (2001), El medio natural en la España Medieval. Actas del I Congreso sobre ecohistoria e Historia Medieval, Cáceres: Universidad.

Clemente Ramos, Julián (2013), "El espacio pecuario en Medellín (1450-1550)", en Anuario de estudios medievales, 43, 2, pp. 505-541.

Clemente Ramos, Julián (2014), "La ganadería en Medellín (1450-1550). Propietarios y cabañas", en Anuario de estudios medievales, 44, 2, pp. 807-844.

Clemente Ramos, Julián (2014), "La sociedad rural en Medellín (c. 1450-1550). Elites, labradores y pobres", en Studia Historica. Historia Medieval, 32, pp. 47-72.

Devís Márquez, Federico (1997), "Señorío y control de pasto en Andalucía: estructura y valor de la renta señorial en Zahara de la Sierra (1484-1556)", Loring García, María Isabel (ed.), Historia social, pensamiento historiográfico y Edad Media. Homenaje al Prof. Abilio Barbero de Aguilera, Madrid: Ediciones del Orto, 475-494.

García Fernández, Manuel (2011), "El Arahal y la «Banda Morisca». La frontera compartida (siglos XIII- XV)”, en Archivo hispalense, t. 94, n. 285-287, pp. 51-67.

García Fernández, Manuel (2005), La Campiña Sevillana y la Frontera de Granada (siglos XIII-XV). Estudios sobre poblaciones de la Banda Morisca. Sevilla.

González Jiménez, Manuel (1996), "La Banda Morisca en el Siglo XIII: el nacimiento de una frontera", pp. 13 23, en Actas de las II Jornadas de Temas Moronenses. La Banda Morisca durante los siglos XIII, XIV y XV. Sevilla.

González Jiménez, Manuel (1987), "Morón de la Frontera a comienzos de s. XV", en Anuario de estudios medievales. Barcelona, CSIC, n. 17, pp. 401-422.

González Jiménez, Manuel. y García Fernández, Manuel (ed.) (1992), Actas capitulares de Morón de la Frontera (1402-1426). Diputación Prov. de Sevilla.

Martín Gutiérrez, Emilio (2015), Paisajes, ganadería y medio ambiente en las comarcas gaditanas. Siglos XIII al XVI, Cádiz-Extremadura: Universidad.

Martín Humanes, José María (2015), "La aldea de Arahal en el tránsito a la modernidad (ss. XV-XVI)", en Archivo hispalense: revista histórica, literaria y artistica, t. 98, n. 297-299, pp. 279-307.

Martín Humanes, José María (2016), Gobernar una villa en la frontera de Granada: Morón de la Frontera (1469-1531). 2 vols. Tesis doctoral inédita.

Martín Humanes, José María (2017), “Ganadería y fiscalidad en la Banda Morisca: los primeros condes de Ureña y el padrón de las yerbas de Morón de la Frontera (1532)", en Historia. Instituciones. Documentos, 44, pp. 211-239.

Morilla Cala, Juan Pablo (1991), "Morón de la Frontera. Un territorio entre dos ámbitos. Aportación al estudio de sus delimitaciones geográficas", en Desde la Frontera. Revista de Temas Moronenses. Morón, 1, pp. 105-136;

Morilla Cala, Juan Pablo (1992), "Proceso y formación del espacio territorial de Morón. Límites, organización y evolución”, en Desde la Frontera. Revista de Temas Moronenses. Morón, 4, pp. 41-83. 
Morilla Cala, Juan Pablo (1996), “Tierras, paisajes y líneas: usos y fronteras en el territorio moronés finimedieval", en La Banda Morisca durante los siglos XIII, XIV y XV,pp. 119-147.

Monsalvo Antón, José María (2010), Comunalismo concejil abulense. Paisajes agrarios, conflictos y percepciones del espacio rural en la Tierra de Ávila y otros concejos medievales, Ávila: Diputación.

Villalonga Serrano, José Luis (2007), Hacer un muy buen pueblo. Del campo de Matrera a Villamartín: análisis de un proceso repoblador en la banda morisca del Reino de Sevilla (1256-1503). Universidad de Sevilla. 